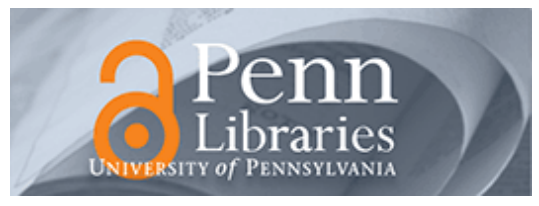

University of Pennsylvania

ScholarlyCommons

Finance Papers

Wharton Faculty Research

2011

\title{
Information Spillovers and Performance Persistence for Hedge Funds
}

Vincent Glode

University of Pennsylvania

Richard C. Green

Follow this and additional works at: https://repository.upenn.edu/fnce_papers

Part of the Finance Commons, and the Finance and Financial Management Commons

\section{Recommended Citation}

Glode, V., \& Green, R. C. (2011). Information Spillovers and Performance Persistence for Hedge Funds. Journal of Financial Economics, 101 (1), 1-17. http://dx.doi.org/10.1016/j.jineco.2011.02.015

This paper is posted at ScholarlyCommons. https://repository.upenn.edu/fnce_papers/359

For more information, please contact repository@pobox.upenn.edu. 


\title{
Information Spillovers and Performance Persistence for Hedge Funds
}

\author{
Abstract \\ We present a simple model that rationalizes performance persistence in hedge fund limited partnerships. \\ In contrast to the model for mutual funds of Berk and Green (2004), the learning in our model pertains to \\ profitability associated with an innovative trading strategy or emerging sector, rather than ability specific \\ to the fund manager. As a result of potential information spillovers, which would increase competition if \\ informed investors were to partner with non-incumbent managers, incumbent managers will let informed \\ investors benefit from increases in estimated profitability following high returns realized with the trading \\ strategy or in the sector. \\ Disciplines \\ Finance | Finance and Financial Management
}




\title{
Information Spillovers and Performance Persistence for Hedge Funds*
}

\author{
Vincent Glode \\ Wharton School \\ University of Pennsylvania \\ and \\ Richard C. Green \\ Tepper School of Business \\ Carnegie Mellon University
}

October 6, 2010

${ }^{*}$ Discussions with Fernando Anjos, Jonathan Berk, Guillaume Plantin, and Fallaw Sowell have been helpful in formulating the ideas in this paper. We also thank an anonymous referee, Yael Hochberg, Steve Kaplan, Dmitry Livdan, Paolo Volpin, and seminar participants at Carnegie Mellon University, Laval University, UCLA, the 2010 AFA Meetings, the 2009 LBS Private Equity Symposium and the 2008 UBC Summer Finance Conference for helpful comments. Vincent Glode gratefully acknowledges financial support from the Social Sciences and Humanities Research Council of Canada, the William Larimer Mellon fund, and the Center for Financial Markets. This paper supersedes an earlier working paper by the same authors titled: "Information Spillovers and Performance Persistence in Private Equity Partnerships." The authors can be reached at the following addresses: Vincent Glode, Wharton School, University of Pennsylvania, 3620 Locust Walk, Suite 2300, Steinberg-Dietrich Hall, Philadelphia, PA 19104, Email: vglode@wharton.upenn.edu and Richard C. Green, Tepper School of Business, Carnegie Mellon University, 5000 Forbes Ave., Pittsburgh, PA, 15213, Email: rcgreen@cmu.edu. 


\title{
Information Spillovers and Performance Persistence for Hedge Funds
}

\begin{abstract}
We present a simple model that rationalizes performance persistence in hedge fund limited partnerships. In contrast to the model for mutual funds of Berk and Green (2004), the learning in our model pertains to profitability associated with an innovative trading strategy or emerging sector, rather than ability specific to the fund manager. As a result of potential information spillovers, which would increase competition if informed investors were to partner with non-incumbent managers, incumbent managers will let informed investors benefit from increases in estimated profitability following high returns realized with the trading strategy or in the sector.
\end{abstract}




\section{Introduction}

Private partnerships, such as hedge funds, have been shown to exhibit persistence in the abnormal performance they generate for investors (see Jagannathan, Malakhov and Novikov 2010) 11 Mutual funds, in contrast, show little performance persistence. The persistence that is evident in mutual fund performance is concentrated in the worst performing funds (see Carhart 1997, Berk and Tonks 2008), where it appears to be largely attributable to inattention by investors in those funds. Such an explanation for persistence in the performance of hedge funds is inconsistent with the nature of the investor base, which consists of institutions and wealthy, relatively sophisticated, individuals. It is also at odds with the facts. Jagannathan, Malakhov and Novikov (2010) document that performance is persistent for hedge funds that perform well, and are thus able to attract new flows.

An explanation for the sensitivity of mutual-fund flows to performance, despite the lack of persistence in performance, is offered by Berk and Green (2004). In that model, investors learn about heterogeneous ability through past returns, but there are decreasing returns to scale in deploying those abilities. In light of this explanation for the behavior of mutual funds, hedge fund partnerships present a puzzle. If flows respond to learning about hedge fund returns, as they appear to do, why do managers not expand the fund or raise their fees to capture the rents going forward?

In this paper, we rationalize performance persistence for hedge funds. Our model is based on evident differences in the institutional setting between mutual funds and hedge funds. We show that persistence can be explained through a need for secrecy. The source of superior returns may not be entirely skills or abilities intrinsic to the manager. Superior returns may also be attributable to strategies or techniques that could be expropriated and exploited by others if they were informed about them. This would explain the use of the limited partnership organizational form for certain types of investment funds.

Hedge funds have a common feature, despite the wide range of investment activities they engage in. They are private. They are organized as limited partnerships and solicit funds from large, "qualified" investors. This frees them from the elaborate disclosure requirements and oversight

\footnotetext{
${ }^{1}$ See also Fung, et al. (2008) who document performance persistence in funds of hedge funds.
} 
mutual funds and publicly traded corporations are subject to. The common choice of organizational form is an endogenous response. A concern that disclosure and oversight, and the associated leakage of information, would erode their ability to generate rents is a natural place to look for a common, primitive determinant of this choice, consistent with empirical findings by Agarwal, et al. (2010). Our model could explain why this organization form is often associated with persistence in excess returns.

The dilemma facing fund managers is illustrated by a widely reported incident involving hedge fund manager John Paulson, who became famous (and very wealthy) by betting against mortgagebacked securities, and one of his former investors who, backed by two investment banks, implemented a similar investment strategy. The Wall Street Journal reported on January 15, 2008:

It was the spring of 2006, and Mr. Paulson, seeking investors for a new fund, gave Mr. Greene a peek at his plan. Mr. Greene didn't wait for the fund to open. He beat his friend to the punch by doing the same complex mortgage-market trade on his own.

The problem evident in the Paulson case, and the concerns evidenced by hedge funds for confidentiality, suggest that what investors learn from past returns is not limited to ability or talent unique to the manager, as assumed by Berk and Green (2004) for the mutual fund industry. Neither are these concerns consistent with models of "soft information" applied to venture capital, which Kaplan and Schoar (2005) show exhibit persistence, as in Hochberg, Ljungqvist and Vissing-Jørgensen (2010). Investors (and managers) may also be learning about the profitability of innovative trading strategies and this information, if known to others, would attract imitation and competition.

Our model considers this possibility in a setting similar to that of Berk and Green (2004). As in their paper, both managers and investors learn about the profitability of the fund through past performance. Future profitability in Berk and Green (2004) depends negatively on assets under management, due to decreasing returns to scale. This is also the case in our model, but in addition the investments made by other partnerships in the same sector or using a similar trading strategy reduce profitability to incumbents going forward. 
In the model, there is an infinite number of potential limited partners (LPs), whereas the number of potential general partners (GPs) is finite. In dealing with investors, the GP makes the first take-it-or-leave-it offer, consistent with the GP's abilities or skills being the ultimately scarce resource. The critical question is why high expected performance going forward should increase the outside option, or reservation price, of the LPs in deciding whether to accept or reject the offer. To illustrate the intuition, we first fix the number of potential GPs exogenously. We later illustrate how the set of potential GPs can be determined endogenously through a fixed cost of entry.

We assume that any party with information useful in estimating future returns credibly and fully discloses it to outsiders when soliciting their participation. The reservation price of an LP being solicited by a GP is determined by the LP's ability to approach new potential GPs and disclose information about the future performance of the trading strategy with which the LP has been investing. Each such disclosure to a new GP, if expected profits are positive, adds a competitor, and thus reduces potential profits for the incumbents.

At each stage of the game, the reservation price of an LP dealing with an offer from a GP is determined by the LP's expected payoff from approaching a new GP and making him an offer. The reservation price of the new GP, responding to an offer from an LP, is determined by his ability to disclose information to, and solicit capital from, a new LP. Thus, the expanding set of competitors that results from the search for alternative partners acts like a discount factor in an alternating-offer bargaining game.

We formulate this game recursively, and solve for the expected payoffs of the various parties as functions of the number of GPs currently informed and investing using the same trading strategy or in the same sector, the number of GPs who could potentially imitate the incumbents, and the current estimated profitability. We then examine conditions under which secrecy is an equilibrium, and the incumbent LP agrees to continue as a partner in a subsequent period. Since the reservation price of the LP is increasing in the expected returns of the strategy going forward, his share of those profits will be as well. Returns to investors will persist across periods for a given hedge fund.

Our focus on the consequences of information spillovers leads us to abstract from many obviously important features of the contracting environment for hedge funds. We ignore asymmetric 
information and moral hazard. As a result, investment is "first-best". The form of the contract between managers and investors is irrelevant. Our intent is not to minimize the importance of these considerations, but we instead focus on returns across periods, rather than contracting over the life of a given fund. If a general partner has positive information about future performance that can be disclosed credibly to investors, why should he not raise fees to the point that investors earn a competitive expected return going forward? Our model provides a simple answer to this question.

An alternative explanation for persistence in private partnerships is offered in Hochberg, Ljungqvist and Vissing-Jørgensen (2010) who focus on venture capital funds. Their explanation is based on the acquisition of "soft information" about the GP's abilities by incumbent LPs, who then hold up the GP, as in models of relationship banking such as Sharpe (1990), Rajan (1992), and von Thadden (2004). The information LPs gain through experience with a GP is assumed to be costly or impossible for the GP to communicate directly to potential investors. Our model is aimed at a similar set of facts, but relies on a completely different mechanism. Both mechanisms may well be at work. Our approach, however, may better capture features of the hedge fund environment, such as concerns for confidentiality, which are at odds with a soft-information story. Absent other frictions, with soft information GPs would pre-commit to disclosure if they could do so. Instead, they appear to go to some lengths to avoid such disclosure.

The central problem studied in our paper involves bargaining when there is a valuable idea or innovation, and two parties with different skills or resources are needed to exploit the opportunity. In this respect, our paper shares concerns with a large literature on the economics of innovation and knowledge transfer, reaching back at least to Arrow (1962). More recent contributions closer to our model include Anton and Yao (1994), Anton and Yao (2002), and d'Aspremont, Bhattacharya, and Gérard-Varet (2000). All of these papers study settings where valuable knowledge is fully or partially disclosed, and the disclosure is verifiable. The difficulties presented by the market for ideas are neatly stated by Anton and Yao, "Ideas are difficult to sell when buyers cannot assess an idea's value before it is revealed and sellers cannot protect a revealed idea." The information in our model has these characteristics. We assume full disclosure is required to engage the necessary help or resources provided by a counter party, and that once such a disclosure is made, the newly 
informed counter party can in turn disclose it to others to solicit their cooperation in exploiting the opportunity. The threat of increased competition determines the relative bargaining power of any two informed counter parties, acting like an endogenous discount factor in an alternating offer game. Thus, our results show that the threat of increased competition helps to facilitate the problem of selling expropriable ideas, the central concern of this literature.

We calibrate the model to unconditional moments of the cross section of hedge funds reported in Jagannathan, Malakhov and Novikov (2010) and Kosowski, Naik and Teo (2007). We then ask if the model can reproduce the persistence in returns observed in the data, and simultaneously match the behaviors implied when the contracts between GP and LP follow a 2/20 rule, popular in the hedge fund industry $!^{2}$ We find that the model can match the observed point estimates of persistence under the theoretical sharing rule or under a $2 / 20$ rule, but not for both. The $2 / 20$ rule, which we apply uniformly to all partnerships, does not allow the GP's return to be quantitatively as responsive to past performance as our theory predicts. When parameterizing our model so that a 2/20 rule would generate an empirically sensible level of performance persistence, our theoretical optimal sharing rule generates a persistence in returns to LPs that is lower than the empirical estimate, but that is still economically significant (about half of it).

The paper is organized as follows. The next section describes the setting and solves for the optimal investment policy in a given strategy or sector. Section 3 models the outside option of each agent and solves for the division of rents between the parties. In Section 4 we derive the model's predictions in terms of secrecy, returns to investors, and fund flows. The robustness of some of these predictions is discussed in Section 5. Section 6 endogenizes the number of potential general partners using a fixed cost of entry. This leads to an interplay between expected future profitability and relative bargaining power, which may produce interesting dynamics when embedded in a dynamic model of entry. Section 7 endogenizes entry in an initial period, and uses simulation to evaluate the quantitative realism of the model's predictions. The last section summarizes and concludes. Proofs are relegated to the Appendix.

\footnotetext{
${ }^{2}$ Under the target compensation scheme, which we call the "2/20 rule", GPs charge their LPs an annual management fee of 2 percent of assets under management and a carried interest of 20 percent of profits, when these profits are positive. See, e.g., Fung and Hsieh (1999) who document the distribution of fees in the hedge fund industry.
} 


\section{The Setting}

There are two types of risk-neutral agents in the model: potential general partners and potential limited partners. The $M$ general partners (GPs) have access to investment opportunities, but no capital. Funds must be obtained from one of the countably infinite identical limited partners (LPs), who have capital but lack the knowledge, networks, time, or experience to independently identify and exploit profitable investment opportunities. For the moment, we take $M$ as exogenously given, but we will later show that a fixed cost of entry can be used, with some added notational complexity, to determine this quantity endogenously. This will tie relative bargaining power to expected returns, producing a richer set of dependencies between past returns and expected performance.

The GP makes a take-it-or-leave-it partnership offer to an LP to raise investment funds. The offer is such that the GP collects the highest possible expected profit from the partnership, subject to satisfying the LP's participation constraint. In this sense, our model is similar to the classic textbook descriptions of corporate financing. The firm acts as a Stackleberg leader in its dealings with competitive financial markets, and under first-best collects the net present value of any investment opportunities, while investors simply earn competitive returns. As Berk and Green (2004) make clear, in such an environment learning should lead flows to respond to past performance, but there is no reason that performance should persist going forward.

Each investment (and its financing) lasts only one period and is continuously scalable. The $i$ th GP invests a positive amount $Q_{i}$ in order to maximize expected profits. Because of diseconomies of scale, the cost of finding good investment opportunities in a given sector or following a given trading strategy increases in $Q_{i}$ much as in Berk and Green (2004). In our setting, however, the costs also increase in the total funds invested in the same trading strategy or sector by all partnerships, as denoted by $\bar{Q} \equiv \sum_{j} Q_{j}$. The cost function facing $G P_{i}$ is $\frac{C}{2} Q_{i} \bar{Q}$. This specification is convenient because it reduces to the quadratic cost function $\frac{C}{2} Q_{i}^{2}$ when the partnership faces no competition, and by adding up the costs incurred by all the partnerships, we obtain the quadratic cost function $\frac{C}{2} \bar{Q}^{2}$. For simplicity, the competitive return is set to zero.

With this specification, the diseconomies of scale in fund management are quadratic in the fund's own investment level, and linear in the investments of the fund's competitors. The diseconomies 
associated with the fund's own investment capture problems scaling up a strategy at the level of a specific fund. As fund size increases, it becomes more difficult to trade without attracting attention. Less liquid assets, which may be more likely to exhibit mispricing, become more difficult to weight significantly within the fund's portfolio. More employees are required to run the fund, resulting in dissipation of talent and costs of delegation. In addition to these fund-specific costs, increased investment in the sector or strategy by competitors results in lower profits for the usual reasons. The form of the cost function we employ yields particularly simple, intuitive, and tractable expressions. We show in Section 5, however, that the qualitative implications of the model survive with more general forms for the cost function, which allow for variation in the relative importance of aggregate versus individual scale.

Most of the analysis in our model involves the dealings between an incumbent GP and LP considering continuation of the partnership. At this point, they have learned about opportunities associated with the trading strategy or sector by participating in previous investments. They are deciding whether to continue their partnership, and if so, how to split the expected profits from subsequent investments. This point in time can be viewed as an intermediate date in a dynamic model, where in a previous period or periods, the incumbent GP and LP have invested in the trading strategy together. In Section 7, when we calibrate the model and explore its quantitative properties, we explicitly employ a three-date, two period model, where continuation, reinvestment, and profit-sharing decisions are determined at the intermediate date.

Reinvesting in a hedge fund will produce a realized return, before accounting for the diseconomies of scale, of $\phi+\epsilon$, where $\phi$ is the expected profitability of the trading strategy, given the information accumulated through participation in previous periods, and $\epsilon$ is a regression error with $E(\epsilon \mid \phi)=0$. We assume that $\phi$ will be positively correlated with past performance, as is natural if there is learning. In Berk and Green (2004), for example, $\phi$ is the posterior expectation of a constant mean resulting from Bayesian updating. The specific form of the correlation with past performance is not important for our results. The question facing us is why expected returns to outside investors should depend positively on $\phi$, which would imply performance persistence. 
Information about $\phi$ is disclosed to potential partners to solicit their participation. For simplicity, we assume that it is $\phi$ itself that is disclosed, but this could be interpreted as verifiable disclosure of a profitable strategy or trading technique, or even as simply revealing the existence or nature of a profitable opportunity. We consider the consequences of partial disclosure of valuable information in Section 5 .

A partnership's realized profit using the trading strategy depends on this return, the size of the investment, and the costs linked to diseconomies of scale. Specifically, the partnership's realized profit is:

$$
Q_{i}[\phi+\epsilon]-\frac{C}{2} Q_{i} \bar{Q}
$$

For a given estimate $\phi$ of the profitability of the trading strategy, each partnership $i$ will choose to invest an amount $Q_{i}$ that maximizes expected profit:

$$
Q_{i} \phi-\frac{C}{2} Q_{i} \sum_{j=1}^{N} Q_{j}
$$

In a symmetric Nash equilibrium, each partnership's optimal investment will be:

$$
Q^{*}(\phi, N)=\frac{2 \phi}{C} \frac{1}{N+1}
$$

and its optimal expected profit, which we denote $\Pi(\phi, N)$, will be:

$$
\Pi(\phi, N)=\frac{2 \phi^{2}}{C} \frac{1}{(N+1)^{2}}
$$

To have $Q^{*}(\phi, N)>0$, we need $\phi>0$. Otherwise, the strategy is not expected to provide any abnormal return, even on the first dollar invested. We focus at this point on $\phi>0$, which is the interesting case. 
Equations (2)-(4) immediately give an expression for returns gross of fees generated by a partnership within a period:

$$
\begin{aligned}
R(\phi, N) & =\frac{\Pi(\phi, N)}{Q^{*}(\phi, N)} \\
& =\phi-\frac{C}{2} \bar{Q} \\
& =\frac{\phi}{N+1} .
\end{aligned}
$$

\section{Information Spillovers}

GPs in our model are of two sorts. Incumbent GPs have experience with the trading strategy, and through this experience enter a period knowing $\phi$. Non-incumbent, potential GPs have the general expertise to enter and compete with incumbents for the strategy's profits, but lack specific knowledge of its potential profitability.

When any informed agent solicits a potential partner, we assume he discloses, fully and credibly, his information about past returns, or equivalently, $\phi$. We abstract from the possibility that a GP would commit fraud or mislead investors through incomplete disclosure, and assume no agent would agree to partner with someone absent full and credible disclosure. We can view the first LP approached by an incumbent GP as the investor who has partnered with the GP in the previous period, but since the GP cannot operate without disclosing $\phi$ to an LP first, it is not essential that the LP has previous experience. As we will see, it is in an incumbent GP's interest to minimize the number of informed parties, so if he has partnered with a particular LP in the past, he would approach that LP first.

We can view the information disclosed as directly pertaining to strategies and choices made by the partnership, which if known to outsiders would attract competition by other financiers. It could also be seen as information about portfolio holdings and the source of past returns. The need for credible disclosure at attract funds appears consistent with reports about industry practice. For example, in an interview with the Wall Street Journal (Yale's Investor Keeps Playbook, 01/13/2009), David Swensen, Yale University's Endowment CIO answered a question about hedge 
fund disclosure with: "We require complete transparency. We either know every position, or we don't invest."

Once disclosure is made to an LP, information is symmetric between the two parties. Similarly, there is no moral hazard in the model. The GP will invest to maximize expected profit (or Net Present Value). The functional form of the contract will therefore be indeterminate, given the shares of the value created accruing to the two parties $\mathrm{S}^{3}$ That is, once disclosure is made we are in a Miller and Modigliani world without contracting frictions except for the possibility of information spillovers. In such an environment, if information in past returns pertains to ability that is unique to the manager, as in Berk and Green (2004), investors will simply earn their reservation expected return of zero going forward. If the possibility of information spillovers alters their reservation price in a direction that reflects the information conveyed by past performance, then we would expect performance to persist.

We are assuming that all of the information required to achieve a given level of excess returns is available to a participating LP. Furthermore, given the information available through disclosure, any GP can implement a given strategy or technique as efficiently as another. This is clearly an abstraction. While LPs require some degree of disclosure, and that information could be of value to potential competitors, it may not be so complete as to allow full expropriation of the knowledge or ideas the original GP possesses. Similarly, some of the GP's ability to generate returns may be specific and inalienable to him. In Section 5 we show how the model can be generalized to allow for the possibilities of partial disclosure or partial replicability.

We also assume that once disclosures are made, bargaining between the two parties takes the simple form of an ultimatum game, which gives all the bargaining power to the proposer, or firstmover (initially, the GP). Despite this disadvantage in bargaining power, we show the LP is able to command a substantial share of the rents associated with the GP's excess expected returns. As our analysis shows, this leads to persistence in returns. While the bargaining protocol we employ is particularly simple and tractable, disclosure and information spillovers would play a similar

\footnotetext{
${ }^{3}$ The homogeneity in contract terms and organizational form across funds might be viewed as inconsistent with our model, which implies the share of value created varies with the GP's history and competitive conditions. However, as we illustrate in Section 7 through simulation, since invested capital and expected profits vary across funds, our model generates considerable cross sectional variation in how profits are shared despite the rigidity of the $2 / 20$ rule.
} 
role with more complex mechanisms. Suppose, for example, that one party who knows he has valuable proprietary information attempts to obtain funds through an auction, or some similar mechanism involving explicit competition between potential partners. Bidders will be reluctant to bid aggressively unless information is disclosed to them about the value of what they are bidding for, and if that information is useful to potential competitors, their bids once they are informed may be lower if they know they can use the information in partnership with others. The ultimatum game allows us to capture these tensions with closed-form expressions because of its relative simplicity. Alternative mechanisms, that gave more bargaining power to an incumbent LP, would not reverse our central results, but rather would increase the share of the surplus LPs were able to command, along with the persistence in their returns.

If past returns are public and are correlated with future profitability, then the fact of past participation in a fund reveals to potential GPs that an incumbent LP has valuable information. The GPs would therefore pay something to participate in a partnership with the LP. What we are assuming is that the winning GP, or any other GP, will not sign a contract with the LP unless and until enough specifics have been disclosed to allow the GP to compete profitably with the original fund, as long as he in turn can find other investors. Alternatively, any agreement the LP and GP sign prior to disclosure is insufficient to ensure that, if the GP defects, at least some of the information disclosed to him will be useful in competing with the original fund.

The mechanics of the model are robust to competition from a defecting GP being less than full replication. They are also robust to the disclosures to the GP, or their transportability if he defects, being only partial. (See Section 5.1 of the paper.) The model would also be robust to a setting where uninformed partners would pay something to participate, but would pay more if more specific and complete information were disclosed. The only thing the model is not robust to would be fully effective non-disclosure or non-compete clauses, or binding commitments to participate in a fund that would be signed before any sensitive disclosures were made. In that situation, the contracting environment would solve the problem of selling ideas directly, and our model would predict not persistence in returns to outside investors. 
Consider an incumbent GP and LP with a shared knowledge of $\phi$ based on the realized returns on a past investment. This information could be fully and credibly disclosed to other, potential, GPs (in finite supply), or LPs (in infinite supply). If the incumbent LP terminates the partnership with his initial GP, the "rejected" GP will be able to solicit a new and so far uninformed LP to invest with during the next period. Similarly, the incumbent LP, with the intent of forming a new partnership, will be able to bring the expected returns available to the attention of a new GP, by disclosing the information in $\phi$.

In the event that they are not satisfied with the profit sharing rule offered by the party they are bargaining with, these disclosures provide solicited agents with outside options. The incumbent GP and LP will nonetheless have an incentive to continue their partnership together in a subsequent period, because involving new partners in the trading strategy would increase competition and reduce the profit earned by each partnership.4

Consider the bargaining problem between a general partner who previously invested in a trading strategy and the limited partner who provided him with capital. Both agents know $\phi(>0)$. The general partner solicits reinvestment funds from the limited partner in the next period by making a take-it-or-leave-it offer. The limited partner's reservation price is determined by his opportunity to inform a non-incumbent GP of $\phi$, and make him a take-it-or-leave-it offer. In turn, the new GP, who is now informed about the profit opportunities, can share that information with a new LP, and make him a take-it-or-leave-it offer, and so on. We assume there are a finite number, $M$, of potential GPs with the skill and expertise needed to implement the trading strategy, and an infinite number of potential LPs. As we will show, this implies the GPs have more bargaining power in this game, since they are supplying the resource that, ultimately, is the scarce one.

An incumbent GP, then, makes a take-it-or-leave-it offer to his original LP that consists of a share of the expected profits $\Pi(\phi, N)$. Since the participation constraint of an agent, whether LP or GP, in a sector or trading strategy with $N$ competing partnerships depends on the profits he

\footnotetext{
${ }^{4}$ Our derivation of endogenous reservation prices as a result of outside opportunities the potential partners have in bargaining with others has some similarities to the bargaining problems considered by Duffie, Gârleanu and Pedersen (2007) in over-the-counter markets.
} 
could make competing with $N+1$ partnerships, we need to use backward induction to solve for participation constraints.

Denote as:

$V(\phi, N)$ Given $\phi$, the expected payoff to a GP making a take-it-or-leave-it offer to an LP, when there are currently $N$ active and informed GPs competing in the market.

$W(\phi, N)$ Given $\phi$, the expected payoff to an informed LP, if there are currently $N-1$ informed GPs, and the LP reveals $\phi$ to a non-incumbent GP through a take-it-or-leave-it offer.

If there are $N$ GPs currently informed and actively pursuing the trading strategy, then profits in a symmetric equilibrium are given by equation (4). An incumbent GP, then, with a successful offer to an LP, whether incumbent or newly informed by the GP, will earn this profit less what he offered the LP. The lowest offer that will succeed must pay the LP what he would obtain if he declined, and sought another non-incumbent GP as a partner, $W(\phi, N+1)$. Therefore:

$$
V(\phi, N)=\Pi(\phi, N)-W(\phi, N+1)
$$

To obtain an expression for $W(\phi, N+1)$, consider the LP who rejects the original GP's offer and seeks a new partner. The LP informs this new, $N+1^{t h}$, GP of $\phi$, and makes a take-it-or-leave-it offer. This offer must be at least as large as the benefit the new GP could obtain by making an offer to a new LP, rationally anticipating that the rejected LP, who is now informed, will seek yet another GP, resulting in $N+2$ competitors. The lowest successful offer then gives the LP the following expected payoff:

$$
W(\phi, N+1)=\Pi(\phi, N+1)-V(\phi, N+2) .
$$

Substituting recursively gives us the following expressions for the expected payoffs for the LP and GP:

$$
V(\phi, N)=\Pi(\phi, N)-\Pi(\phi, N+1)+V(\phi, N+2),
$$


and

$$
W(\phi, N)=\Pi(\phi, N)-\Pi(\phi, N+1)+W(\phi, N+2)
$$

Solving the above system of difference equations requires terminal values for the expected payoff functions. Recall the total number of potential GPs is $M$. When there are already $M$ GPs informed and competing, then the LPs have no outside option beyond a competitive financial return, which is assumed to be zero. They will accept any offer from a GP that pays them this expected return, so:

$$
W(\phi, M+1)=0,
$$

and

$$
\begin{aligned}
V(\phi, M) & =\Pi(\phi, M) \\
& =\frac{2 \phi^{2}}{C} \frac{1}{(M+1)^{2}} .
\end{aligned}
$$

Suppose, then, that there are $M-1$ GPs currently competing against each others. An offer made by a GP to an LP will be accepted if the LP gets more than he would making an offer to the $M^{\text {th }}$ GP, rationally anticipating that the rejected GP, who is informed about $\phi$, will seek yet another LP, resulting in $M$ competitors. But once the $M^{\text {th }}$ and final GP is informed he can make an offer to one of the remaining LPs, who have only the competitive outside option. Therefore:

$$
W(\phi, M)=0,
$$

and

$$
\begin{aligned}
V(\phi, M-1) & =\Pi(\phi, M-1) \\
& =\frac{2 \phi^{2}}{C} \frac{1}{M^{2}} .
\end{aligned}
$$

The critical players in the system are the GPs and LPs when there are $M-2$ competitors. At this point the LP has bargaining power. An LP approaching the $M-1^{\text {th }}$ GP can make an offer 
that will be accepted if it exceeds the profit he would earn seeking a new partner, anticipating the rejected LP will also seek a new partner, so that the $M-1^{\text {th }}$ GP will end up competing with $M$ other GPs. Therefore:

$$
W(\phi, M-1)=\frac{2 \phi^{2}}{C}\left(\frac{1}{M^{2}}-\frac{1}{(M+1)^{2}}\right)>0 .
$$

An offer made by a GP to an LP will be accepted if the LP gets more than $W(\phi, M-1)$. Therefore:

$$
V(\phi, M-2)=\frac{2 \phi^{2}}{C}\left(\frac{1}{(M-1)^{2}}-\frac{1}{M^{2}}+\frac{1}{(M+1)^{2}}\right),
$$

which is larger than $V(\phi, M-1)$ when $\phi>0$.

By iterating these steps, we can solve for the general form of the payoff functions $V(\phi, N)$ and $W(\phi, N)$. If $N<M$, then:

$$
V(\phi, N)=\frac{2 \phi^{2}}{C} \sum_{j=1}^{A(N, M)} \frac{(-1)^{j+1}}{(N+j)^{2}}
$$

and

$$
W(\phi, N)=\frac{2 \phi^{2}}{C} \sum_{j=1}^{B(N, M)} \frac{(-1)^{j+1}}{(N+j)^{2}} .
$$

where $A(N, M)=M-N$ and $B(N, M)=M-N+1$, when $M-N$ is odd, and $A(N, M)=M-N+1$ and $B(N, M)=M-N$, when $M-N$ is even.

\section{Model Predictions: Secrecy, Return Persistence, and Fund Flows}

In this section we derive predictions from our model in terms of information secrecy, return persistence, and fund flows. We focus on the case in which $\phi>0$, so net positive investment in the trading strategy is optimal. To facilitate these derivations, we first present Lemma 1.

Lemma 1 Let $F(N, N+K)=\sum_{j=1}^{K}(-1)^{j+1} f(N+j)$ where $K \in \mathcal{N}^{++}, N \in \mathcal{N}^{++}$, and $f(\cdot)$ is a function satisfying $f(N)>f(N+1)>\ldots>f(N+K-1)>f(N+K) \geq 0$. Then $F(N, N+K)>0$.

Proof: See Appendix for all proofs. 
We now establish that each agent who can make a take-it-or-leave-it offer at any point will act in equilibrium to avoid the information spillovers that would result from soliciting outside potential partners. For "secrecy" to be an equilibrium, we must show both parties obtain higher expected payoffs with less competition. The next proposition accomplishes this.

Proposition 1 The payoff functions, $V(\phi, N)$ and $W(\phi, N)$, are weakly decreasing in $N$, and are strictly decreasing in $N$ for $N<M$.

This result implies that an agent making a take-it-or-leave-it offer will always find it optimal to satisfy his initial partner's participation constraint, keeping the estimated profitability of the trading strategy as secret as possible. The benefits from keeping the competition to a minimum outweigh any gains from reducing the solicited partner's bargaining power by increasing the number of informed agents. That is, secrecy is an equilibrium.

Consequently, the first offer an incumbent GP makes to his initial LP will be good enough to ensure that it is accepted. An incumbent LP will therefore expect to receive from reinvesting in the fund a payoff of:

$$
W(\phi, N+1)=\frac{2 \phi^{2}}{C} \sum_{j=1}^{B(N+1, M)} \frac{(-1)^{j+1}}{(N+1+j)^{2}} .
$$

Expected returns to LPs are then straightforward to calculate. The LP contributes capital $Q^{*}(\phi, N)$ and received an expected payoff of $W(\phi, N+1)$. From equations (3) and (17), the per dollar expected return is:

$$
\frac{W(\phi, N+1)}{Q^{*}(\phi, N)}=\phi \sum_{j=1}^{B(N+1, M)}(-1)^{j+1} \frac{N+1}{(N+1+j)^{2}}
$$

Proposition 2 The expected payoff $W(\phi, N+1)$ and return $\frac{W(\phi, N+1)}{Q *(\phi, N)}$ to a LP are positive and increasing in $\phi$ when $\phi>0$ and strictly positive and strictly increasing in $\phi$ when $N<M-1$. 
This result establishes that the outside option for an LP is positive and increasing in $\phi$. Any successful offer by an incumbent GP to an LP, whether new or incumbent, will pay positive expected profits that are increasing in estimated future profitability. Thus, as long as expected profitability increases with past returns, we have established that expected returns to LPs will show persistence across periods.

In our model, fund flows will follow performance, as long as expected future profitability $\phi$ increases with past returns.

Proposition 3 Aggregate flows invested in a trading strategy or sector:

1. increase in estimated future profitability $\phi$

2. increase in the degree of competition $N$, and

3. are more responsive to estimated profitability when there is more competition.

Flows respond to higher expected profitability for the same reasons they do in Berk and Green (2004). While marginal costs rise with fund size, and with aggregate industry flows, the higher expected returns compensate investors for these increased costs.

Increased competition leads partnerships to invest more aggressively because with more competitors, each fund internalizes less of their impact on aggregate flows, and the resulting increase in costs. By the same logic, the model predicts that flows are more responsive to performance the more competitive the sector.

The set of possible partners for a GP in our model is unlimited, while the number of potential partners for an LP is finite. As a result, the GPs in our model always have more bargaining power and command a greater share of the profits. They are in relatively scarce supply. The following result formalizes the intuitive link between this relative scarcity and the share of value accruing to both partners. Recall that $V(\phi, N)$ is the expected payoff to a GP, with $N$ active incumbents, while 
$W(\phi, N+1)$ is the expected profit that accrues to an LP. When there are $M$ active partnerships, the LP's only outside options is a competitive return of zero, so the difference between his payoff and that of the GP is the value of the partnership. The proof of the proposition shows by a recursive argument that this difference is a lower bound for the difference between the expected profits to the GP and LP for any $N$.

Proposition 4 For any $N$, the difference between the payoff functions for the GP and $L P, V(\phi, N)-$ $W(\phi, N)$ is constant, and $V(\phi, N)>W(\phi, N+1)$.

The impact of increased competition on the relative bargaining power of the GP and the LP is more complex. In Figure 1 we plot the share of total profits accruing to the GP, $\frac{V(\phi, N)}{\Pi(\phi, N)}$, and the LP, $\frac{W(\phi, N+1)}{\Pi(\phi, N)}$. Evidently, these are not monotonic in the degree of competition. The LP's relative bargaining power is tied both to the number of potential GPs available, and to the extent to which profits dissipate with additional competition. These quantities are changing at different rates, creating the non-monotonic relationship evident in the figure.

Figure 2 depicts the relationship between the degree of competition, $N$, the expected return to the partnership as a whole, and the expected return to the LP. The expected return to the LP decreases monotonically. As $N$ increases, the expected payoff to the LP decreases. The capital invested also falls, but not by enough since the partnership fails to internalize the impact on aggregate profits, and this problem becomes more severe with more competitors.

The model also suggests that future performance increases with fund size and is lower for firsttime funds. From Proposition 2 we know that the expected return to the LPs is positive and increasing in $\phi$. From equation 3 we know the same is true of $Q^{*}(\phi, N)$. Therefore, fixing $N$ and $M$ - that is, controlling for the bargaining power of the LPs - return and size will be positively associated in the cross section. Variations in $Q^{*}$ will help predict the expected profit the LP will collect from reinvesting in the fund. 
The logic behind the model also suggests expected returns to LPs should be lower for first-time funds. The GP in the model makes the first take-it-or-leave-it offer. In the absence of information spillovers the LP would earn a competitive return of zero. When reinvesting, the LP expects to collect $W(\phi, N+1)$ if $\phi>0$ and zero otherwise. Accordingly, in the initial investment the GP could, in principle, offer the LP a negative expected profit equal to $-E[W(\phi, N+1) \cdot I(\phi>0)]$ and the LP's ex-ante participation constraint would bind. The expected profit from the initial investment will therefore be smaller than the expected profit from the subsequent investment. Evidently, this relationship also holds for expected returns, given the signs of each term. It seems unlikely, of course, that LPs will enter partnerships without some disclosure of proprietary information to them, but as long as more information accrues to them through experience in the sector or with the strategies pursued by the GP, we would expect the LP's bargaining power to increase over time.

\section{Robustness}

So far, we have kept our model as frictionless as possible in order to maximize its tractability and transparency. We now consider the robustness of the model's qualitative implications with respect to variation in some of the main assumptions.

Three central elements are at work in our model:

1. In the cross section of funds, potential expected returns going forward must be correlated with past returns. This plays the same role in our model as in Berk and Green (2004).

2. The capacity to generate excess returns must be something the incumbent LP can, to some extent, take with him on defecting from an existing partnership. This, along with the first item above, ensures the LP's outside option increases in past returns.

3. There must be frictional costs of some sort that dissipate rents when the LP defects. These costs ensure secrecy is an equilibrium.

The simplifying assumptions in our model serve to make the interaction between these three elements particularly stark. The LP is assumed to be able to fully communicate information acquired 
through past participation and thus completely replicate with an outside GP whatever he could achieve with the incumbent GP (item 2). None of the ability to create expected returns is specific to the manager. The only cost of going to an outsider is increased competition (item 3). This cost acts like an endogenously determined, non-constant discount factor in a repeated offer game, steadily diminishing the shared surplus as the set of informed parties grows.

\subsection{Partial Expropriation or Disclosure}

It seems plausible that some portion of superior performance is due to strategies or technologies that potential competitors could replicate, but there may also be a portion of performance that is attributable to skills or human capital specific to a manager or management team. For example, implementing a fixed-income strategy may require quantitative screening methods to identify trading opportunities, but may also require experienced traders who have acquired a network of personal contacts that facilitate efficient trading. The former is relatively easy to copy, while the latter is not.

This can be modeled in our setting by assuming that if the expected profitability parameter for an incumbent partnership is $\phi$, then only $\lambda \phi, 0<\lambda<1$ can be realized by an LP partnering with a non-incumbent GP.

Similarly, we have assumed to this point that, by virtue of participating in a fund, an incumbent LP obtains disclosures that provide full knowledge of the technologies or strategies that generate the expected profitability of $\phi$. It may be viewed as more plausible that the disclosures required by participating LPs give them only a portion of the information needed, but enough that they can capture $\lambda \phi$ in partnership with others.

In either case, the central arguments in our analysis go through with minor changes. The steps given by equations (1)-(4), using $\lambda \phi$ instead of $\phi$ yield partnership-wide expected profits of $\Pi(\lambda \phi, N)=\lambda^{2} \Pi(\phi, N)$.

When dealing with his initial LP, an incumbent GP needs to offer at least

$$
W(\lambda \phi, N+1)=\lambda^{2} W(\phi, N+1)
$$


to ensure the LP's participation. The GP will then collect

$$
\Pi(\phi, N)-\lambda^{2} W(\phi, N+1)
$$

which represents the profits he can earn by continuing the partnership, less the share of the profits that his initial LP can earn by soliciting a non-incumbent GP to invest in the same sector, but with an estimated profitability of $\lambda \phi$ due to the difficulty of replicating the incumbent GP's strategy.

Thus, partial replication or disclosure in our model preserves all the profit-sharing profit functions up to a multiplier $\lambda^{2}$, except for the incumbent GP's expected profits when making an initial offer: $\Pi(\phi, N)-\lambda^{2} W(\phi, N+1)$. So all our earlier results still hold qualitatively, but quantitatively speaking, the incumbent GP has more bargaining power because he can implement the profitable strategy better than non-incumbent GPs. Incumbent GPs would prefer to operate in environments where $\lambda$ is low, or in other words, with minimal disclosure or strategies that are difficult to imitate. As we argue in the introduction, a minimum level of disclosure or imitability should however be expected for most hedge fund investments.

\subsection{Diseconomies of Scale}

The cost function we have employed yields simple, closed-form expressions for optimal investment levels and equilibrium expected profits. It also prescribes very specific forms for returns to scale and competitive externalities. Partnership profits fall linearly in competitors' investments levels, and fall quadratically in their own investment. The decrease in profits due to investment by other funds can be viewed as the consequence of increased competition. The decreasing returns in the fund's own investment captures non-scalabilities such as trading costs, or the increased coordination and delegation costs associated with a larger management team.

The relative importance of these different factors for fund returns might vary by situation or by sector. At the cost of algebraic complexity, we can employ more general forms for the cost function that allow for variation in the relative importance of individual versus aggregate investment in the 
sector. Specifically, suppose expected profits to a fund are of the form:

$$
Q_{i} \phi-A Q_{i}^{a} \bar{Q}^{b}
$$

where $a \geq 1$ and $b \geq 1$ govern the relative importance of the fund and its competitors on the diseconomies of scale.

The first-order condition is for optimal investment is

$$
\phi-A\left[a \frac{Q_{i}^{a} \bar{Q}^{b}}{Q_{i}}+b \frac{Q_{i}^{a} \bar{Q}^{b}}{\bar{Q}}\right]=0
$$

Symmetry requires $Q_{i}=Q^{*}$ and $\bar{Q}=N Q^{*}$. Evaluating the first-order condition at these values gives equilibrium $Q^{*}$ as

$$
Q^{*}=\left[\frac{\phi}{A N^{b-1}(a N+b)}\right]^{\frac{1}{a+b-1}}
$$

Comparing (24) with the equilibrium investment for our simpler specification, (3), reveals that they have similar qualitative features. Investment increases in the expected profitability parameter, $\phi$, and falls with the degree of competition, $N$.

Expected profits in a symmetric equilibrium will also exhibit behaviors similar to those present in our simpler specification. Evaluating (22) at 24) yields, after some simplification, the following expression for equilibrium expected profits:

$$
\begin{aligned}
\phi Q^{*}-A N^{b}\left(Q^{*}\right)^{a}\left(Q^{*}\right)^{b} & =\phi\left[\frac{\phi}{A N^{b-1}(a N+b)}\right]^{\frac{1}{a+b-1}}-A N^{b}\left[\frac{\phi}{A N^{b-1}(a N+b)}\right]^{\frac{a+b}{a+b-1}} \\
& =\left[\frac{\phi}{A N^{b-1}(a N+b)}\right]^{\frac{a+b}{a+b-1}}\left[A N^{b-1}(a N+b)-A N^{b}\right] .
\end{aligned}
$$

Our results that secrecy is an equilibrium and that LPs are able to capture some portion of the expected fund excess returns going forward depend on four properties of the profit function:

1. Individual fund expected profits are concave in $Q_{i}$.

2. Equilibrium expected profits are positive for $\phi>0$ and any $N$. 
3. Equilibrium expected profits are decreasing in the amount of competition, $N$.

4. Equilibrium expected profits go to zero as $N \rightarrow \infty$.

For the simple specification of diseconomies of scale we have employed in earlier sections, these properties are evident from inspection of equations (1)-(4). We show in the Appendix that they also hold for the more general cost function as well.

\section{Endogenous Entry at Intermediate Dates}

The analysis to this point takes the number of potential GPs as fixed and finite, which imparts a bargaining advantage to them in their dealings with LPs. In this section we illustrate how the set of potential GPs at the intermediate date can be endogenously determined through a fixed cost of entry. As the number of competing GPs increases, per-partnership profits fall. If there is a fixed cost for non-incumbent GPs to enter, this will limit the set of potential, non-incumbent GPs. That limit will, in turn, reflect the expected profitability of the trading strategy or sector, $\phi$, leading to a dependence between past returns and the relative bargaining power of the two parties. Nevertheless, the functions describing the division of rents between the GP and the LP retain the same form, with a few notational complications.

Suppose that non-incumbent GPs face a fixed cost of $k$ upon implementing the trading strategy or entering the sector. The timing of events is as follows. First, the new GP receives information about $\phi$ from an LP, along with an offered sharing rule. Next, the GP makes the entry decision, and either incurs the fixed cost $k$ or walks away and receives a payoff of zero. Third, the GP can reject the offer from the initial LP, and solicit financing from a new LP while disclosing $\phi$. Thus, the entry cost is naturally interpreted as effort or expenditure required for a new GP to reach a point where he can effectively solicit funding and implement the trading strategy in question.

Once the entry cost is paid, symmetric equilibria determining profits and investment in the industry are the same as before. If there are $N-1$ informed GPs competing for profits, then upon 
learning the value of $\phi$ a new GP will enter only if:

$$
\begin{aligned}
\Pi(\phi, N)-k & =\frac{2 \phi^{2}}{C} \frac{1}{(N+1)^{2}}-k \\
& \geq 0 .
\end{aligned}
$$

The maximum number of potential entrants is given by the $M^{*}(\phi)$ that exhausts the profitability of the industry. Thus, $M^{*}(\phi)$ is the maximum integer $M$ such that:

$$
\frac{2 \phi^{2}}{C} \frac{1}{(M+1)^{2}}-k \geq 0
$$

or equivalently, such that:

$$
M \leq \phi \sqrt{\frac{2}{k C}}-1 .
$$

Now suppose an informed GP makes an offer to his former LP when there are N informed GPs targeting the same trading strategy or sector. The GP will have to offer the LP at least $W(\phi, N+1)$ and will make:

$$
V(\phi, N)=\Pi(\phi, N)-W(\phi, N+1)
$$

If the LP rejects the offer, he knows that the informed GP has already paid the entry cost, hence will enter as long as $\phi>0$. The LP will have to make an offer to an uninformed GP of at least $V(\phi, N+2)-k$, the new GP's expected payoff if he were to reject the offer. Thus:

$$
\begin{aligned}
W(\phi, N+1) & =\Pi(\phi, N+1)-k-[V(\phi, N+2)-k] \\
& =\Pi(\phi, N+1)-V(\phi, N+2) .
\end{aligned}
$$

In order for the LP to have an outside option, he needs to ensure that entering the sector or implementing a trading strategy with an uninformed GP, given that the GP who made him the earlier offer will also compete, promises positive expected profits, that is:

$$
\Pi(\phi, N+1) \geq k
$$


At $M^{*}(\phi)$, the maximum number of partnerships that keeps the sector or trading strategy profitable, the informed LP will not be able to convince an uninformed GP to enter a partnership with him because the $M^{*}(\phi)+1^{\text {th }}$ partnership will not be profitable. Therefore:

$$
W\left(\phi, M^{*}(\phi)+1\right)=0
$$

An informed GP at $M^{*}(\phi)$ is sure that no uninformed GP will ever pay $k$ to enter the sector, hence the informed GP has all the bargaining power at $M^{*}(\phi)$. Thus:

$$
V\left(\phi, M^{*}(\phi)\right)=\Pi\left(\phi, M^{*}(\phi)\right)
$$

which is greater or equal to $k$, by definition of $M^{*}(\phi)$.

Similarly, if an informed LP was to reject a GP offer at $M^{*}(\phi)-1$ and make an offer to a $M^{*}(\phi)^{t h}$ GP, this previously uninformed GP would know that by rejecting the LP's offer, the rejected LP would be unable to find a $M^{*}(\phi)+1^{\text {th }}$ GP. Hence:

$$
W\left(\phi, M^{*}(\phi)\right)=0
$$

and

$$
V\left(\phi, M^{*}(\phi)-1\right)=\Pi\left(\phi, M^{*}(\phi)-1\right)
$$

By recursion, we can find the exact same value functions $V(\cdot, \cdot)$ and $W(\cdot, \cdot)$ as in our model with $M$, except that $V(\cdot, \cdot)$ represents the payoff to an incumbent GP and $V(\cdot, \cdot)-k$ represents the payoff to a non-incumbent GP.

Figures 3 and 4 show how the relative bargaining power and expected returns vary with expected profitability $\phi$ when there is one incumbent partnership. As Figure 3 illustrates, the LP has no bargaining power when expected profits are low, because the fixed cost would deter entry by other potential partners. Any new entrant would dissipate profits to a point where the entry cost could not be recovered. (This point corresponds to $N=M$ in the model without endogenous entry.) As expected profits rise, bargaining power for the LP increases, but at a decreasing rate. The increase 
in the number of potential GPs who could enter rises, but each new potential entrant dissipates industry profits less. The increase in bargaining power as the trading strategy's profitability rises translates into higher expected returns for the LP, as evident in Figure 4. Both the rents available, and the LP's ability to extract them increase with $\phi$.

\section{Endogenous Entry at Initial Date with a Calibrated Example}

This section describes how we can endogenize entry at an initial date, before any learning has occurred, and through simulation generate a cross section of partnership returns with which to examine the quantitative properties of the model.

There are two periods, and three dates, $t=0,1,2$. The entry cost at the beginning of the initial period is $k_{0}$, which we assume to be greater than the entry cost at the intermediate date, $k_{1}$. When entering at the intermediate date, the GP has been informed by the LP about the profitability of the trading strategy or sector. The fact that the LP has already invested, through a competing GP, in the trading strategy or sector makes the subsequent entry with a non-incumbent GP less costly or difficult.

The return to the trading strategy from $t=0$ to $t=1$ (on the first dollar invested) is $r_{1}=\rho+\epsilon_{1}$, where $\epsilon_{1}$ is distributed normally with mean zero and variance $\sigma^{2}$. The expected return $\rho$ is unkown to both managers and investors, who have shared priors that it is normally distributed with mean $\phi_{0}$ and variance $\eta^{2}$. The information set of investors at the initial date is the number of partnerships using the trading strategy. Incumbent partners observe their payoffs over the initial period, and since strategies are common knowledge they can infer $r_{1}$. They then update as Bayesians to estimate the expected profitability going forward as:

$$
\phi_{1}=\left(\frac{\frac{1}{\eta^{2}}}{\frac{1}{\eta^{2}}+\frac{1}{\sigma^{2}}}\right) \phi_{0}+\left(\frac{\frac{1}{\sigma^{2}}}{\frac{1}{\eta^{2}}+\frac{1}{\sigma^{2}}}\right) r_{1} .
$$

Given this estimate of potential profitability, we can calculate the number of GPs who, if informed, would enter the sector or implement the trading strategy at the intermediate date. This 
is $M^{*}\left(\phi_{1}\right)$, the maximum integer such that:

$$
M \leq \phi_{1} \sqrt{\frac{2}{k_{1} C}}-1
$$

Given the estimated profitability $\phi_{0}$, which is known by every agent, the number of partnerships $N^{*}\left(\phi_{0}\right)$ to enter in the first period will be the maximum integer $N$ such that:

$$
\Pi\left(\phi_{0}, N\right)+E\left[\Pi\left(\phi_{1}, N\right) \cdot I\left(\phi_{1}>0\right)\right]-k_{0} \geq 0
$$

Notice that if $\phi_{1}$ is sufficiently small compared to $\phi_{0}$, then $M^{*}\left(\phi_{1}\right) \leq N^{*}\left(\phi_{0}\right)$ and the LP has no bargaining power at the intermediate date. How small $\phi_{1}$ has to be for that situation to occur depends on how the cost of entry at the intermediate date, $k_{1}$, compares with the cost of entry at the initial date, $k_{0}$. We would expect $k_{0}$, the entry cost in the first period, without special information about the sector or trading strategy, to be greater than $k_{1}$, the entry cost with the information shared by an incumbent LP.

The second term in the equilibrium entry condition, (27), is the expectation of a nonlinear function of $\phi_{1}$, and does not admit a closed-form solution. It is however straightforward to calculate numerically, which allows us to solve numerically for $N^{*}\left(\phi_{0}\right)$. We can then simulate two periods of returns for a large cross section of artificial funds, and in this way evaluate the model's ability to quantitatively capture salient empirical facts about hedge fund investing.

We simulate a cross section of 20,000 hedge fund partnerships. Each partnership invests in a trading strategy or sector for one period, learns about its profitability, and then decides whether to reinvest for the next period. Each simulated partnership is a representative of its own trading strategy or sector. All funds are identical initially, and therefore operate with the same number $\left(N^{*}\left(\phi_{0}\right)-1\right)$ of competitors. First-period returns are drawn independently, expectations are updated, $M^{*}\left(\phi_{1}\right)$ is determined for each fund, and the expected profits are split according to the bargaining model between the LP and GP. We then draw returns again to determine realized profits for those partnerships that survived and were sufficiently profitable to continue. 
The artificial cross section of all first-period funds and the surviving second-period funds is used to compare the simulated outcomes to empirically estimated moments from Agarwal, Daniel, and Naik (2009), Jagannathan, Malakhov and Novikov (2010) and Kosowski, Naik and Teo (2007).

Our model makes predictions as to how expected profits are shared between GPs and LPs, but the sharing contract in terms of realized profits is indeterminate. In the data, a particular contract predominates (see Fung and Hsieh 1999). Under the so-called "2/20 rule" GPs charge investors an annual management fee of 2 percent of assets under management and a carried interest of 20 percent of profits. One question we pose, therefore, as a quantitative test of the model, is how close applying a 2/20 contract for all funds comes to implementing the optimal solutions from our model in the simulated data. That is, does the division of surplus using this specific contract approximate, both unconditionally and conditional on previous returns, the division of surplus implied by our model?

To estimate the performance persistence of a hedge fund, Jagannathan, Malakhov and Novikov (2010) regress its risk-adjusted return from a three-year period over that from the preceding (nonoverlapping) three-year period. We therefore normalize each period in our model as a three-year period. As our benchmark fee structure for each period, we use a "6/20" rule, which is basically a " $2 / 20 "$ rule, but accumulated for three years.

The parameter values used in our simulations are presented in the table below. Keep in mind that the measure of expected profitability $\phi_{0}$ applies only to the first dollar invested. Average realized profitability will be much lower.

\section{Table 1: Parameter values used in our simulation}

\begin{tabular}{lcc}
\hline \hline & Symbol & Value \\
\hline Diseconomy-of-scale cost & $C$ & 0.0007 \\
Entry cost at initial date $(\$ \mathrm{M})$ & $k_{0}$ & 30 \\
Entry cost at intermediate date $(\$ \mathrm{M})$ & $k_{1}$ & 10 \\
Unconditional mean of profitability & $\phi_{0}$ & 0.25 \\
S.D. of profitability & $\eta$ & 0.275 \\
S.D. of idiosyncratic noise & $\sigma$ & 0.05 \\
\hline
\end{tabular}


Assuming normally distributed excess returns simplifies the learning mechanism in our simulation. It has the disadvantages of producing excess returns that are smaller than $-100 \%$ with positive probability. Keep in mind, however, that this applies to realized excess returns. The frequency with which limited liability would be violated would be much lower for realized total return, though of course it is still possible. The probability of this event would decrease if we were to choose lower values for $\eta$ and $\sigma$, but this would also decrease the probability of partnerships being dissolved at the intermediate date. We use a relatively low value for the idiosyncratic noise in order to have cross-sectional differences in funds that are mostly driven by differences in expected profitability.

The six parameter values were chosen through trial and error to approximate eight empirical moments from past studies. We interpret the unconditional moments as applying to the pooled simulated outcomes (initial and follow-on returns). Table 2 lists the moments from empirical studies and from our calibrated simulations. The first three moments in the table are the same under the model, whether the form of the contract with investors is indeterminate or a $2 / 20$ rule. The restriction we impose in the fourth row is that the net of fee return be the same in the first period for the model and for the $2 / 20$ contract. This does not correspond to an empirical moment, but will restrict the parameters. The last two rows relate an empirically estimated moment to simulated moments for both the model and to returns under the 2/20 contract, and thus represent four moments to be matched. Thus, the six parameters are chosen in an attempt to match eight moments, one each for the first four rows of the table and two each for the last two rows.

Table 2: Empirical estimates and simulated moments.

\begin{tabular}{lccc}
\hline \hline & & \multicolumn{2}{c}{ Simulation } \\
& Data & Model & $2 / 20$ \\
\hline Avg. fund size (in \$M) & 213 & 206 \\
3-Year Attrition Rate & $12 \%$ & \multicolumn{2}{c}{$17.9 \%$} \\
Avg. difference between gross and net returns & $2.30 \%$ & \multicolumn{2}{c}{$2.60 \%$} \\
Avg. annual net-of-fee return (1st period only) & & $-1.00 \%$ & $-0.95 \%$ \\
Avg. annual net-of-fee return & $\sim 0 \%$ & $-0.30 \%$ & $-0.45 \%$ \\
Persistence Coefficient for LP Returns & 0.215 & 0.11 & 0.24 \\
\hline
\end{tabular}


As is evident from the table, our model does a reasonable job of fitting the unconditional moments, but it predicts too little persistence in returns when compared to empirical estimates. The moments the model closely approximates are as follows.

1. The average fund size is is $\$ 206 \mathrm{M}$, which is in line with the subsample averages reported in Jagannathan, Malakhov and Novikov (2010) (between $\$ 170 \mathrm{M}$ and $\$ 255 \mathrm{M}$ ), and their overall average of $\$ 213 \mathrm{M}$.

2. The attrition rate from one three-year period to the next is $17.9 \%$ in our cross section, higher than the $12 \%$ average rate that Jagannathan, Malakhov and Novikov (2010) report.

3. The gross-of-fee return is about $2.3 \%$ higher than the net-of-fee return, as in Agarwal, Daniel, and Naik (2009). The former is the return that the GP and the LPs share. The latter is the return to the LPs.

4. The average net-of-fee return for initial, first period funds earned by LPs should be the same for the model and under the $2 / 20$ rule. In our simulations they are very close. Since in this parameterization the $2 / 20$ rule provides has LPs investing in the first period with an expected return close to that from our model's optimal contract, meeting this restriction allows us to use the realized return to an LP given by a $2 / 20$ rule to tie down the realized return an LP would receive in our model. (Recall that the functional form of our model's optimal contract is indeterminate.)

5. The average annual net-of-fee return under the model's optimal profit-sharing rule in line with the estimate in Kosowski, Naik and Teo (2007) that is not significantly different from zero. This is the average abnormal return earned by investors in hedge funds, both initial funds and follow-up funds.

6. The net-of-fee return for the $2 / 20$ rule is also close to zero. The $2 / 20$ rule in our simulated cross section results in the average LP collecting an abnormal profit of $\$ 1.1 \mathrm{M}$ over the two periods, which we argue is close to the zero-profit prediction of our model, given that this $\$ 1.1 \mathrm{M}$ profit requires an average investment of $\$ 206 \mathrm{M}$ over three or six years. 
Our model understates the observed level of persistence in the data, while applying the $2 / 20$ rule generates persistence closer to the empirical estimates. We now turn to the reasons for these results.

The number $M\left(\phi_{1}\right)$ of GPs who, if solicited by an informed LP at the intermediate date, would be willing to invest increases with estimated profitability. This, in turn, increases the bargaining power of incumbent LPs. Figure 5 plots this relationship and the optimal number of partnerships $N^{*}\left(\phi_{0}\right)$ to invest in the trading strategy or sector at the initial date (in our simulation $N^{*}\left(\phi_{0}\right)=3$ ). The figure can be divided in three regions: a region where initial returns are so low that all agents stop investing, a region where returns are sufficiently high that uninformed GPs would enter if they became informed, and an intermediate region where only the GPs who have already paid their entry cost are willing to reinvest for the second period. In our model, the only incumbent LPs with bargaining power are those who invested in funds in the region with high returns. As a result, those LPs should be the only ones able to collect a share of their partnership's positive expected excess profits. This prediction is consistent with Jagannathan, Malakhov and Novikov (2010) who find that performance persistence is concentrated among better performing hedge funds.

Figure 6 plots the relationship our model predicts between returns earned from the first threeyear period and expected returns to be collected by incumbent LPs in the second three-year period. The figure also plots the returns each simulated LP would collect, on average, if it were facing a 2/20 compensation scheme instead (using, for each simulated initial three-year period, 20,000 simulated three-year scenarios). Similarly, Figure 7 compares the expected revenue per dollar of assets under management an incumbent GP would collect based on our model and on a 2/20 rule. These figures suggest that, under the current parameterization, our model's optimal contract generates more cross-sectional variation in the expected share of the profits going to the GPs than does a uniformly applied 2/20 rule. Since the GP and LP share the total expected payoff, this in turn dampens the variation in the returns going to the LPs. A way to quantify these cross-sectional variations is through the use of cross-sectional regressions. For example, in our simulated sample of partnerships, regressing a partnership's second-period return to LPs from a 2/20 rule over its first-period returns to LPs and a constant yields a coefficient of 0.24 , in line with the coefficients 
reported by Jagannathan, Malakhov and Novikov (2010) (i.e., between 0.22 and 0.30). Running the same regression, but using second-period returns predicted by our model rather than by a $2 / 20$ rule, yields a coefficient of 0.11 , almost half the persistence we get with the $2 / 20$ rule.

To summarize these findings, at parameters chosen to match the unconditional moments of the pooled cross section, such as average fund size and survival probability, we can ensure the right level of persistence for the uniformly applied 2/20 contract. Our model, while producing significant levels of performance persistence, is unable to match the empirically observed level of persistence. Thus, relative to our model, performance is more persistent for actual funds because, either flows in the data are less responsive than in the model or because the $2 / 20$ contract, when applied uniformly to all partnerships, is too rigid for the GP's share to fully respond to information about future profits, or both.

There are two ways to increase the persistence in the returns to LPs in our model. First, by limiting the number of initial entrants, one can decrease the responsiveness of flows to performance. A monopoly, for example, would reinvest less aggressively than a duopoly. Proceeding in this direction, however, also increases the persistence in returns based on the $2 / 20$ rule. Alternatively, we can manipulate the parameters that control how returns are split between the LP and GP, to give the LP more bargaining power at the intermediate date. The difficulty here is that increasing the LP's share of the second-period profits, as it reduces the GP's expected profit, must be offset with lower average profits for the LP in the first three-year period. This pushes the average return to the LP in the first three-year period below the levels from the $2 / 20$ rule. So, while our model could match the observed point estimates, the $2 / 20$ returns under such a parameterization would overstate them.

I is also evident from Figure 6 it is evident that some funds in our sample would not survive if a 2/20 rule was implemented. Second-period funds with relatively small, but positive $\phi$ would be profitable according to our model, but rational and informed LPs would refuse to finance such investments in a 2/20 environment. The fixed fee of two percent per year would end up exhausting more than the expected returns available, and LPs would expect to lose money on their investment. For this reason, we compare the persistence coefficients generated by our model and by a $2 / 20$ rule 
when only considering funds that would survive given both profit sharing schemes. For these funds, our model generates a level of performance persistence of 0.14 whereas the $2 / 20$ rule generates a coefficient of 0.15 . That is, considering funds that are simultaneously viable for LPs in a $2 / 20$ rule and in our model significantly reduces the difference in the implications between our model and a $2 / 20$ rule. This, in turn, allows the calibrated model to more closely match observed outcomes of persistence without pushing the persistence under the $2 / 20$ rule to implausible levels.

Qualitatively, our model captures a number of features of the hedge-fund environment. What differences between the environment in the real world and the theoretical setting might explain the quantitative differences between our model's predictions and the data? Alternatively, why does the $2 / 20$ contract seem to be so ubiquitous when it fails to fully implement the efficient outcomes?

First, the savings in contracting and negotiation costs associated with employing a standardized $2 / 20$ contract may offset the loss in value to the partnerships from implementing a more complex contract that would yield outcomes closer to those in the model. The rigidities in the GP's share are costly to the partnerships ex-ante, but may not be costly enough to warrant greater contractual complexity.

Second, flows in the real world may be less responsive to information about expected profitability than they are in our model due to such frictions as investor inattention or search costs in identifying alternatives. If flows are insufficiently responsive, then the decreasing returns that lower expected returns in later periods will not act as quickly as they do in the model. In this case, the theoretical benchmark may be understating the persistence associated with efficient outcomes, accounting for these frictions.

Third, real-world implementation of the $2 / 20$ contract is likely to be less homogeneous than in our calibrated example. Our oversimplified implementation of the $2 / 20$ rule ignores many of the variations in actual contract terms, and this may lead it to overstate the rigidity in the GP's share across periods. Contract heterogeneity has been documented in detail for private equity funds, for example in Kaplan and Strömberg (2003). For hedge funds, Schwarz (2007) documents that GPs managing funds with high returns in the past are more likely to increase their incentive fees in the future. This behavior lowers the effective persistence coming from the profit sharing rules we see 
in practice, compared to our uniformly applied 2/20 rule, and reduces the gap with the persistence coming from our model.

Of course, all these factors may be at work simultaneously. For example, if rigidity in flows explains why actual funds show more persistence than the efficient contract in our model would imply, that must be associated with greater contract heterogeneity as otherwise the less responsive flows would drive up persistence in the $2 / 20$ contract.

\section{Conclusion}

In this paper, we present a simple model of hedge funds. Its central features are based on evident differences in the institutional setting between mutual funds and hedge funds. In contrast to the model for mutual funds in Berk and Green (2004), the learning in our model pertains to profitability associated with a new trading strategy or an emerging sector, rather than just with ability specific to the manager. This leads to performance persistence because incumbent investors benefit, along with managers, from increases in the estimated profitability of a given investment associated with high realized returns. Sharing information rents with initial investors guarantees incumbent managers that their investors will not leave them at an intermediate date to form partnerships with nonincumbent managers, resulting in information spillovers and competition that dissipates profits.

While the model clearly oversimplifies many features of the environment, when calibrated to the empirical moments from past studies, it captures quantitatively many important aspects of the observed outcomes. However, returns to LPs show less persistence in our model than in the data. The source of this discrepancy appears to be the rigidity of a uniformly applied $2 / 20$ contract, as the model predicts more variation in GP returns due to past performance than can be achieved through the $2 / 20$ sharing rule. 


\section{APPENDIX}

Proof of Lemma 1: First, consider $F(N, N+K)$ when $K$ is even. We can rewrite $F(N, N+K)$ as $F(N, N+2 \cdot T)$ where $T \equiv \frac{K}{2} \in \mathcal{N}^{++}$:

$$
\begin{aligned}
F(N, N+2 \cdot T) & =\sum_{j=1}^{2 T}(-1)^{j+1} f(N+j) \\
& =\sum_{j=1}^{T}[f(N+2 j-1)-f(N+2 j)] .
\end{aligned}
$$

For any $j \in \mathcal{N}^{++}$, the term $[f(N+2 j-1)-f(N+2 j)]$ is strictly positive because $f(N+2 j-1)>$ $f(N+2 j)$. Hence, for any $T \in \mathcal{N}^{++} F(N, N+2 \cdot T)$ is a sum of strictly positive number and is also strictly positive.

It remains to consider $F(N, N+K)$ when $K$ is odd. We can write:

$$
F(N, N+K)=F(N, N+K-1)+(-1)^{K+1} f(N+K)
$$

Since $K+1$ is even, the last term is positive, and the first term is positive by the above argument for $K$ even. Hence, for any combination of $N \geq 1$ and $K \geq 1, F(N, N+K)$ will be strictly positive.

Proof of Proposition 1; For $N>M-2$ the result is self-evident from the expressions for the terminal values in equations (11)-(15). When $N \leq M-2$, we must separately consider the cases when $M-N$ is even and odd.

When $M-N$ is odd, and $M-N \geq 2$, we must establish the following inequalities hold:

$$
V(\phi, N)=\frac{2 \phi^{2}}{C} \sum_{j=1}^{M-N} \frac{(-1)^{j+1}}{(N+j)^{2}}>\frac{2 \phi^{2}}{C} \sum_{j=1}^{M-N} \frac{(-1)^{j+1}}{(N+1+j)^{2}}=V(\phi, N+1)
$$


and

$$
W(\phi, N)=\frac{2 \phi^{2}}{C} \sum_{j=1}^{M-N+1} \frac{(-1)^{j+1}}{(N+j)^{2}}>\frac{2 \phi^{2}}{C} \sum_{j=1}^{M-N-1} \frac{(-1)^{j+1}}{(N+1+j)^{2}}=W(\phi, N+1)
$$

We first show that the inequality in $(\mathrm{A}-4)$ is equivalent to $(\mathrm{A}-3)$. Subtracting the final term from the left-hand side of $(\mathrm{A}-4)$ we obtain:

$$
W(\phi, N)-\frac{2 \phi^{2}}{C} \frac{(-1)^{M-N+1}}{(N+(M-N+1))^{2}}=\frac{2 \phi^{2}}{C} \sum_{j=1}^{M-N} \frac{(-1)^{j+1}}{(N+j)^{2}}
$$

which is identical to the left-hand side of $(\mathrm{A}-3)$. Subtracting the same expression from the righthand side of $\mathrm{A}-4$ gives:

$$
\begin{aligned}
W(\phi, N+1)-\frac{2 \phi^{2}}{C} \frac{(-1)^{M-N+1}}{(N+(M-N+1))^{2}} & =\frac{2 \phi^{2}}{C} \sum_{j=1}^{M-N-1} \frac{(-1)^{j+1}}{(N+j+1)^{2}}+\frac{2 \phi^{2}}{C} \frac{(-1)^{M-N}}{(N+(M-N+1))^{2}} \\
& =\frac{2 \phi^{2}}{C} \sum_{j=1}^{M-N} \frac{(-1)^{j+1}}{(N+j+1)^{2}}
\end{aligned}
$$

which is identical to the right-hand side of $(\mathrm{A}-3)$. Thus, if we can demonstrate that $(\mathrm{A}-3)$ holds, it will follow that $\mathrm{A}-4$ holds.

Subtracting $V(\phi, N+1)$ from $V(\phi, N)$, we see that, assuming $\phi>0, \mathrm{~A}-3$ ) will hold when:

$$
\sum_{j=1}^{M-N}(-1)^{j+1}\left[\frac{1}{(N+j)^{2}}-\frac{1}{(N+1+j)^{2}}\right]>0
$$

The term $\left[\frac{1}{(N+j)^{2}}-\frac{1}{(N+1+j)^{2}}\right]$ can be reduced to $\frac{2(N+j)+1}{(N+j)^{2}(N+j+1)^{2}}$ and is strictly decreasing in $j$, given that:

$$
\begin{aligned}
\frac{\partial}{\partial j}\left[\frac{2(N+j)+1}{(N+j)^{2}(N+j+1)^{2}}\right] & =\frac{2(N+j)(N+1+j)-[2(N+j)+1][2(N+1+j)+2(N+j)]}{(N+j)^{3}(N+1+j)^{3}} \\
& =-\frac{[2(N+j)+1][(N+1+j)+2(N+j)]}{(N+j)^{3}(N+1+j)^{3}} \\
& <0 .
\end{aligned}
$$


Consequently, Lemma 1 implies that the sum in equation (A-7) is strictly positive, making the inequality always satisfied.

Now consider the case where $M-N$ is even, and $M-N>2$. Then, we must establish:

$$
V(\phi, N)=\frac{2 \phi^{2}}{C} \sum_{j=1}^{M-N+1} \frac{(-1)^{j+1}}{(N+j)^{2}}>\frac{2 \phi^{2}}{C} \sum_{j=1}^{M-N-1} \frac{(-1)^{j+1}}{(N+1+j)^{2}}=V(\phi, N+1),
$$

and

$$
W(\phi, N)=\frac{2 \phi^{2}}{C} \sum_{j=1}^{M-N} \frac{(-1)^{j+1}}{(N+j)^{2}}>\frac{2 \phi^{2}}{C} \sum_{j=1}^{M-N} \frac{(-1)^{j+1}}{(N+1+j)^{2}}=W(\phi, N+1) .
$$

Condition $\mathrm{A}-9 \mathrm{n}$ is identical in form to inequality $\mathrm{A}-4$, and the same steps (subtracting the final term on the LHS from both sides) will show it holds if $\mathrm{A}-10$ holds. Inequality $\mathrm{A}-10$, however, is identical in form to condition $\mathrm{A}-3$, which we have already shown to hold as a consequence of $\mathrm{A}-8$.

Proof of Proposition 2; First, if $N \geq M-1$, then $W(\phi, N+1)$ and $\frac{W(\phi, N+1)}{Q *(\phi, N)}$ equal zero for any value of $\phi$. If however $N<M-1$, the result is implied by Lemma 1 and the facts that $\frac{1}{(N+1+j)^{2}}$ and $\frac{N+1}{(N+1+j)^{2}}$ are both strictly positive and strictly decreasing in $j$.

Proof of Proposition 3: Total flows to GPs in the trading strategy or sector are $\bar{Q}=N Q^{*}(\phi, N)$, which by (3) can be written as:

$$
\bar{Q}=\frac{2 \phi}{C} \frac{N}{N+1},
$$

which is, evidently, increasing in $\phi$.

The second item follows if:

$$
H(N)=\frac{N}{N+1}
$$


is increasing in $N$. Differentiating,

$$
H^{\prime}(N)=\frac{(N+1)-N}{(N+1)^{2}}=\frac{1}{(N+1)^{2}}>0
$$

The third item follows if:

$$
\frac{\partial \bar{Q}}{\partial \phi \partial N}>0
$$

Since $\bar{Q}$ is linear in $\phi$, however, this result will hold if $H^{\prime}(N)>0$, which was just established.

Proof of Proposition 4: From equations (6) and (7), evaluated at $N$ rather than $N+1$, we have:

$$
V(\phi, N)-W(\phi, N)=V(\phi, N+1)-W(\phi, N+1)
$$

for all $N$. From (11) and (12):

$$
V(\phi, M)-W(\phi, M)=\frac{2 \phi^{2}}{C} \frac{1}{(M+1)^{2}}
$$

Finally, Proposition 1 shows $W(\phi, N)$ is decreasing in $N$, so that:

$$
\begin{aligned}
V(\phi, N)-W(\phi, N+1) & \geq V(\phi, N)-W(\phi, N) \\
& =\frac{2 \phi^{2}}{C} \frac{1}{(M+1)^{2}} \\
& >0
\end{aligned}
$$

as long as $M$ is finite.

\section{Properties of Generalized Profit Function}

1). Profit function is concave in $Q_{i}$. 
Differentiating the left-hand side of the first-order condition, 23, gives

$$
-A Q_{i}^{a} \bar{Q}^{b}\left[\frac{a(a-1)}{Q_{i}^{2}}+\frac{2 a b}{Q_{i} \bar{Q}}+\frac{b(b-1)}{\bar{Q}^{2}}\right]
$$

Since $a \geq 1$ and $b \geq 1$ this expression will clearly be negative for positive investment levels.

2). Equilibrium profits are positive.

As shown in the text, equilibrium expected profit is

$$
\begin{aligned}
\phi Q^{*}-A N^{b}\left(Q^{*}\right)^{a}\left(Q^{*}\right)^{b} & =\phi\left[\frac{\phi}{A N^{b-1}(a N+b)}\right]^{\frac{1}{a+b-1}}-A N^{b}\left[\frac{\phi}{A N^{b-1}(a N+b)}\right]^{\frac{a+b}{a+b-1}} \\
& =\left[\frac{\phi}{A N^{b-1}(a N+b)}\right]^{\frac{a+b}{a+b-1}}\left[A N^{b-1}(a N+b)-A N^{b}\right] .
\end{aligned}
$$

The final term is positive if

$$
A N^{b-1}(a N+b)>A N^{b}
$$

or if

$$
\frac{a N+b}{N}>1
$$

which will hold for any $N$ as long as $a \geq 1$ and $b>0$.

3). Equilibrium profits are decreasing in $N$.

After some algebraic manipulation, the RHS of the first line in equation A-19 can be rewritten as follows:

$$
\phi^{\frac{a+b}{a+b-1}}\left[\frac{1}{A N^{b}}\right]^{\frac{1}{a+b-1}}\left[\left(\frac{1}{a+\frac{b}{N}}\right)^{\frac{1}{a+b-1}}-\left(\frac{1}{a+\frac{b}{N}}\right)^{\frac{a+b}{a+b-1}}\right] .
$$

The first term in brackets is decreasing in $N$. Differentiating the second term in brackets by $N$ (and re-arranging) yields:

$$
\begin{gathered}
\frac{-b}{N^{2}} \frac{1}{(a+b-1)}\left[(a+b)\left(a+\frac{b}{N}\right)^{-\frac{a+b}{a+b-1}-1}-\left(a+\frac{b}{N}\right)^{-\frac{1}{a+b-1}-1}\right]= \\
\frac{-b}{N^{2}} \frac{1}{(a+b-1)} \frac{1}{\left(a+\frac{b}{N}\right)^{\frac{a+b}{a+b-1}}}\left[\frac{a+b}{a+\frac{b}{N}}-1\right]
\end{gathered}
$$


The first term is negative. All the other terms in brackets and in parentheses are positive, including the last one as long as $N>1$. Hence, equilibrium profits are decreasing in $N$ when $a \geq 1, b \geq 1$, and $A>0$.

4). Equilibrium profits go to zero as $N$ goes to infinity.

Inspection of $(\mathrm{A}-22$ reveals that the first term in brackets goes to zero and the two factors in the last brackets approach finite positive limits as $N \rightarrow \infty$. This means that profits go to zero as $N$ goes to infinity. 


\section{References}

Agarwal, Vikas, Naveen D. Daniel, and Narayan Y. Naik, 2009, "Role of Managerial Incentives and Discretion in Hedge Fund Performance," Journal of Finance 64: 2221-2256.

Agarwal, Vikas, Wei Jiang, Yuehua Tang, and Baozhong Yang, 2010, "Uncovering Hedge Fund Skill from the Portfolio Holdings They Hide," working paper, Columbia University.

Anton, James J. and Dennis A. Yao, 1994, "Expropriation and inventions: Appropriable rents in the absence of property rights," American Economic Review 84: 190-209.

Anton, James J. and Dennis A. Yao, 2000, "The sale of ideas: Strategic disclosure, property rights, and contracting," Review of Economic Studies 69: 513-531.

Arrow, Kenneth J., 1962, "Economic welfare and the allocation of resources for invention," in The Rate and Direction of Inventive Activity: Economic and Social Factors, NBER: 609-626.

d'Aspremont, Claude, Sudipto Bhattacharya and Louis-André Gérard-Varet, 2000, "Bargaining and Sharing Innovative Knowledge," Review of Economic Studies 67: 255-271.

Berk, Jonathan B. and Richard C. Green, 2004, "Mutual Fund Flows and Performance in Rational Markets," Journal of Political Economy, 112: 1269-1295.

Berk, Jonathan B. and Ian Tonks, 2008, "Return Persistence and Fund Flows of the Worst Performing Mutual Funds," working paper, Haas School of Business, University of California at Berkeley.

Carhart, M., 1997, "On Persistence in Mutual Fund Performance," Journal of Finance, 52: 57-82.

Duffie, D., N. Gârleanu and L. H. Pedersen, 2007, "Valuation in Over-the-Counter Markets," Review of Financial Studies, 20: 1865-1900.

Fung, William, David A. Hsieh, Narayan Y. Naik and Tarun Ramadorai, 2008, "Hedge Funds: Performance, Risk, and Capital Formation," Journal of Finance, 63: 1777-1803. 
Fung, William, and David A. Hsieh,, 1999, "A primer on hedge funds," Journal of Empirical Finance, 6, 309-331.

Hochberg, Yael, Alexander Ljungqvist, and Annette Vissing-Jørgensen, 2010, "Informational Holdup and Performance Persistence in Venture Capital," working paper, Northwestern University.

Jagganathan, Ravi, Alexey Malakhov, and Dmitry Novikov, 2010, "Do Hot Hands Exist Among Hedge Fund Managers? An Empirical Evaluation," Journal of Finance 65: 217-255.

Kaplan, Steven N. and Antoinette Schoar, 2005, "Private Equity Performance: Returns, Persistence, and Capital Flows," Journal of Finance 60: 1791-1823.

Kaplan, Steven N. and Per Strömberg, 2003, "Financial Contracting Theory Meets the Real World: An Empirical Analysis of Venture Capital Contracts," Review of Economic Studies 70: 281315 .

Kosowski, Robert, Narayan Y. Naik, Melvyn Teo, 2007, "Do hedge funds deliver alpha? A Bayesian and bootstrap analysis" Journal of Financial Economics 84: 229-264.

Rajan, Raghuram, 1992, "Insiders and Outsiders: The Choice between Informed and Arm's Length Debt," Journal of Finance 47: 1367-1400.

Schwarz, Christopher, 2007, "Hedge Fund Fees," working paper, University of Massachusetts.

Sharpe, S. A., 1990, "Asymmetric Information, Bank Lending and Implicit Contracts: A Stylized Model of Customer Relationships," Journal of Finance 45: 1069-1087.

von Thadden, Earnst-Ludwig, 2004, "Asymmetric Information, Bank Lending and Implicit Contracts: The Winner's Curse," Finance Research Letters 1: 11-23. 


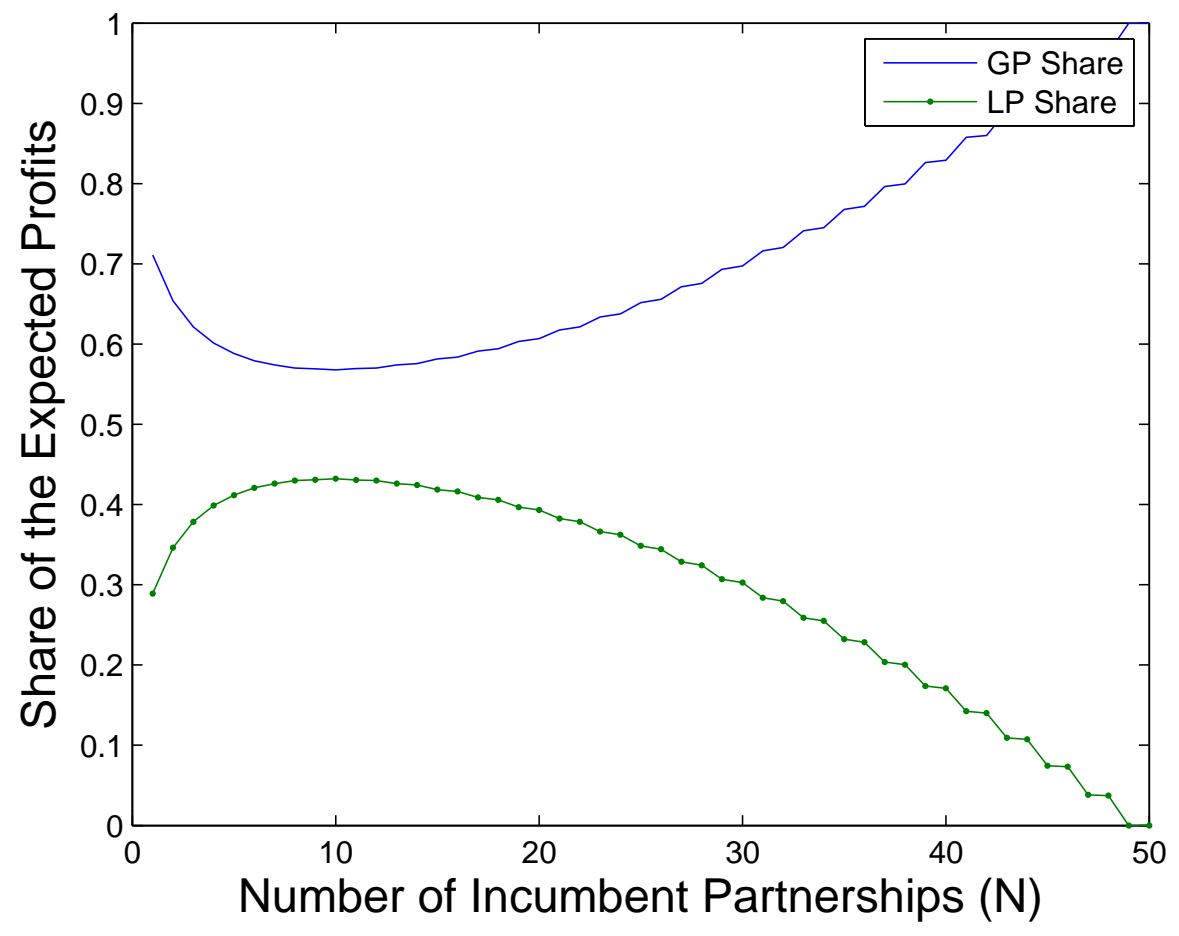

Figure 1: Fraction of total profits accruing to the expert and financier, as a function of $N$, the number of active partnerships. Parameter values are $M=50$ (fixed supply of potential GPs), $\phi=1$ (expected profitability), and $C=2$ (coefficient in cost function). 


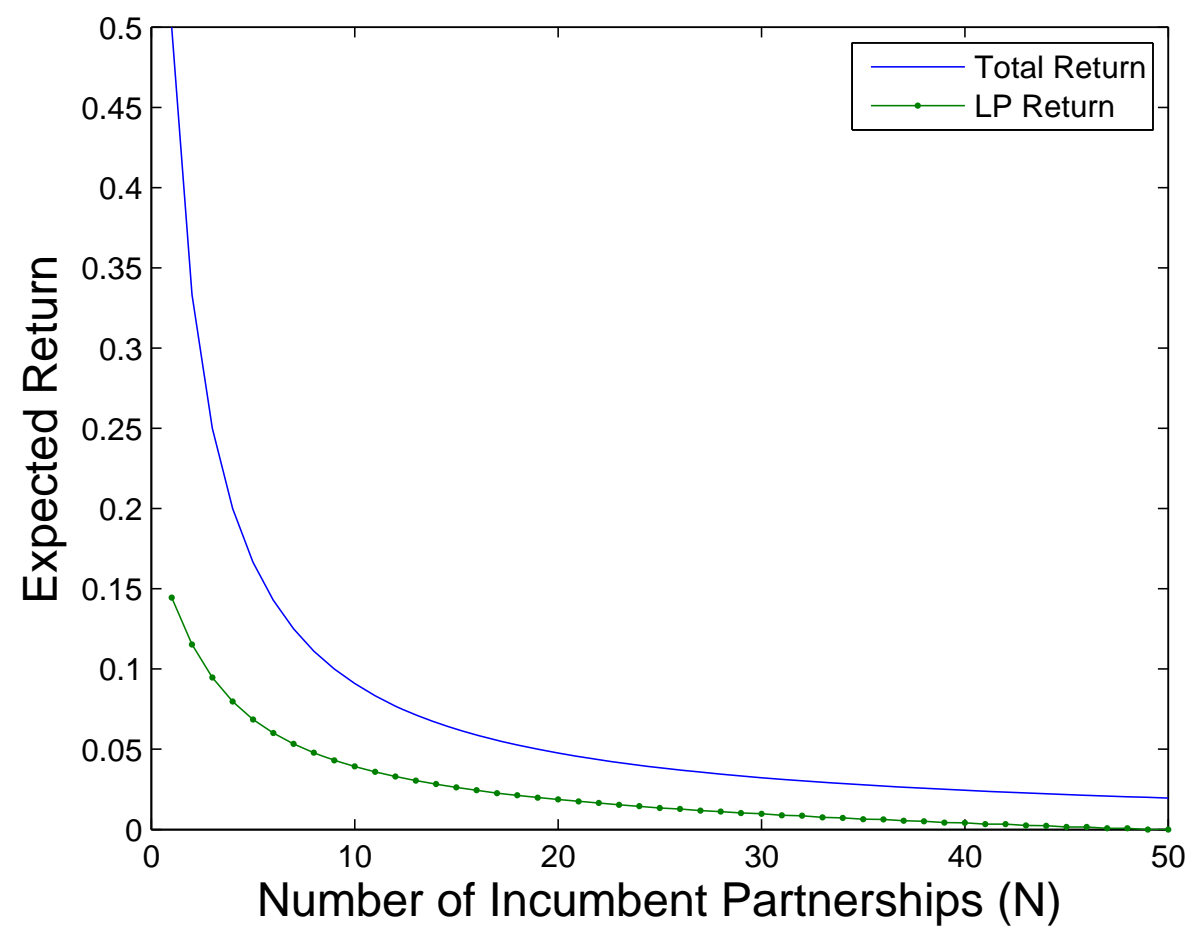

Figure 2: Expected return to the partnership and to the LP, as a function of $N$, the number of active partnerships. Parameter values are $M=50$ (fixed supply of potential GPs), $\phi=1$ (expected profitability), and $C=2$ (coefficient in cost function). 


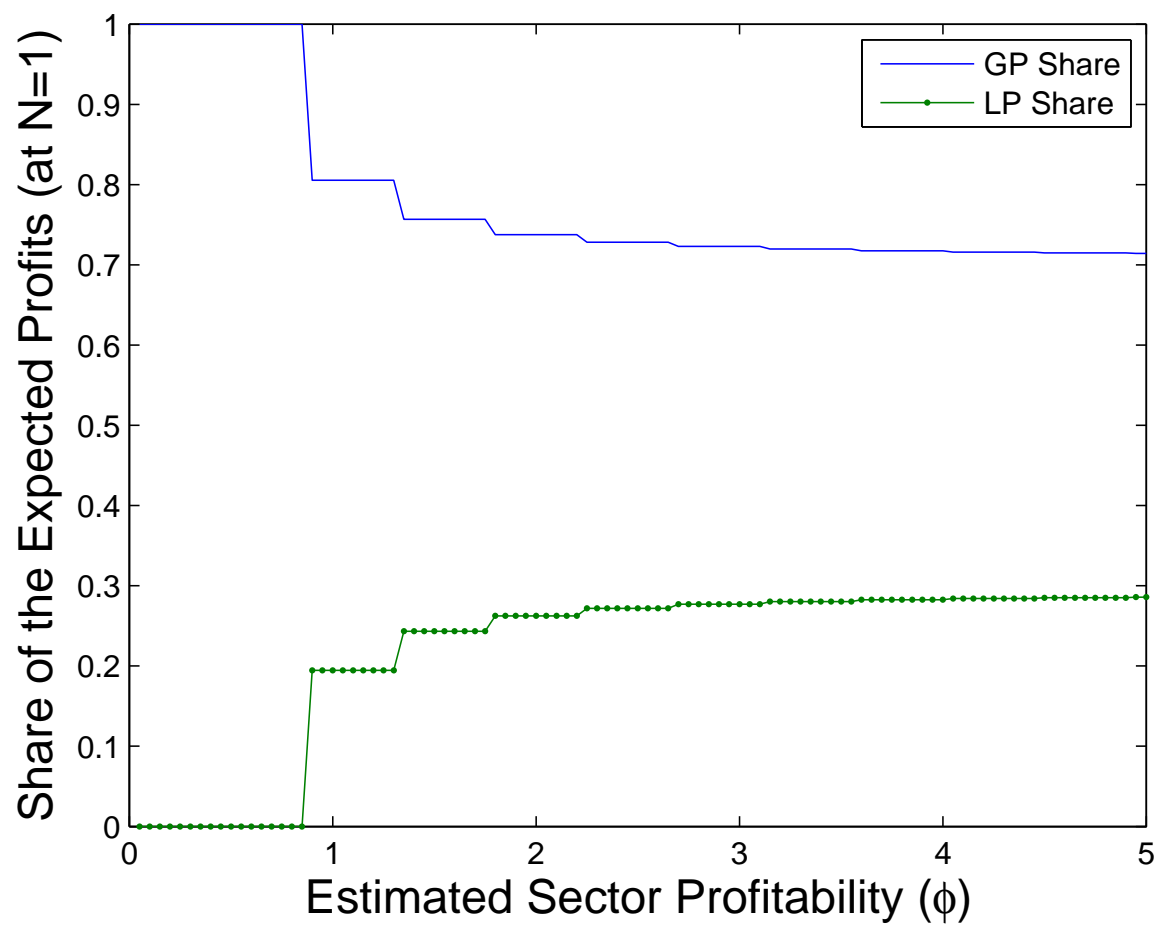

Figure 3: Share of profits accruing to the expert and the financier, as a function of $\phi$, the expected profitability of the trading strategy, with endogenous entry. Parameter values are $N=1$ (number of incumbent GPs), $k=0.02$ (fixed cost of entry), and $C=2$ (coefficient in cost function). 


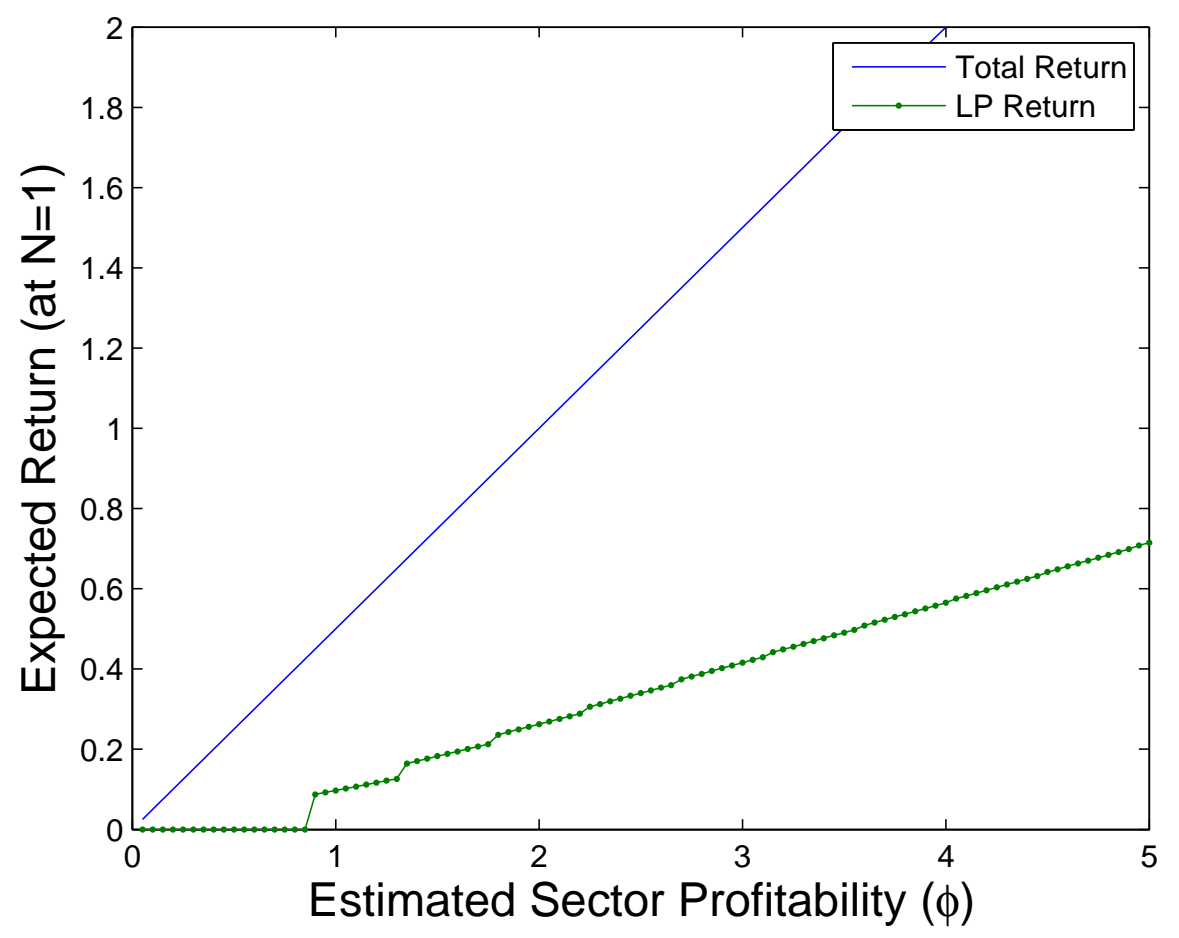

Figure 4: Expected return to the partnership and to the LP, as a function of $\phi$, the expected profitability of the sector, with endogenous entry. Parameter values are $N=1$ (number of incumbent GPs), $k=0.02$ (fixed cost of entry), and $C=2$ (coefficient in cost function). 


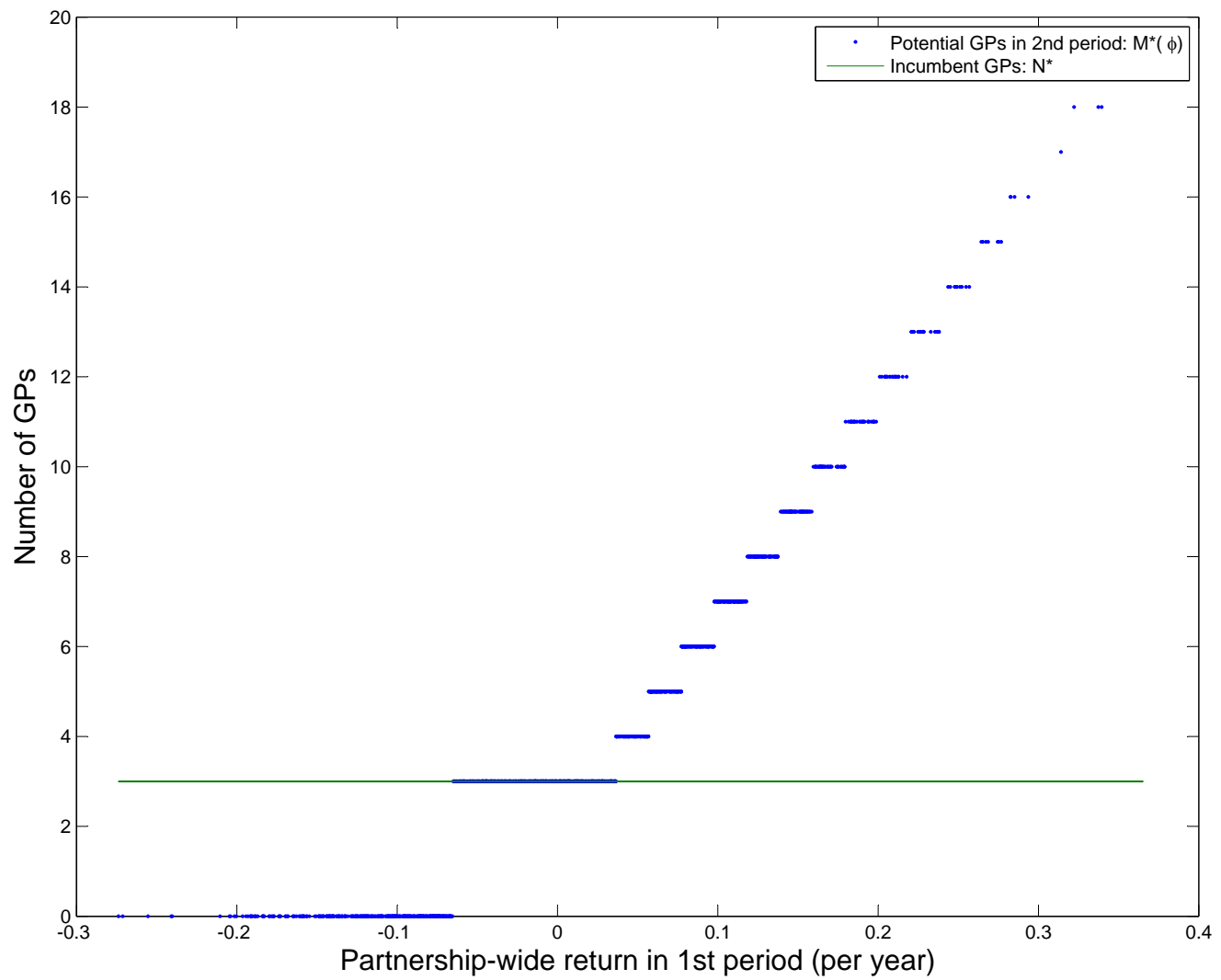

Figure 5: Number of potential GPs and incumbent GPs as a function of first-period partnershipwide excess return. 


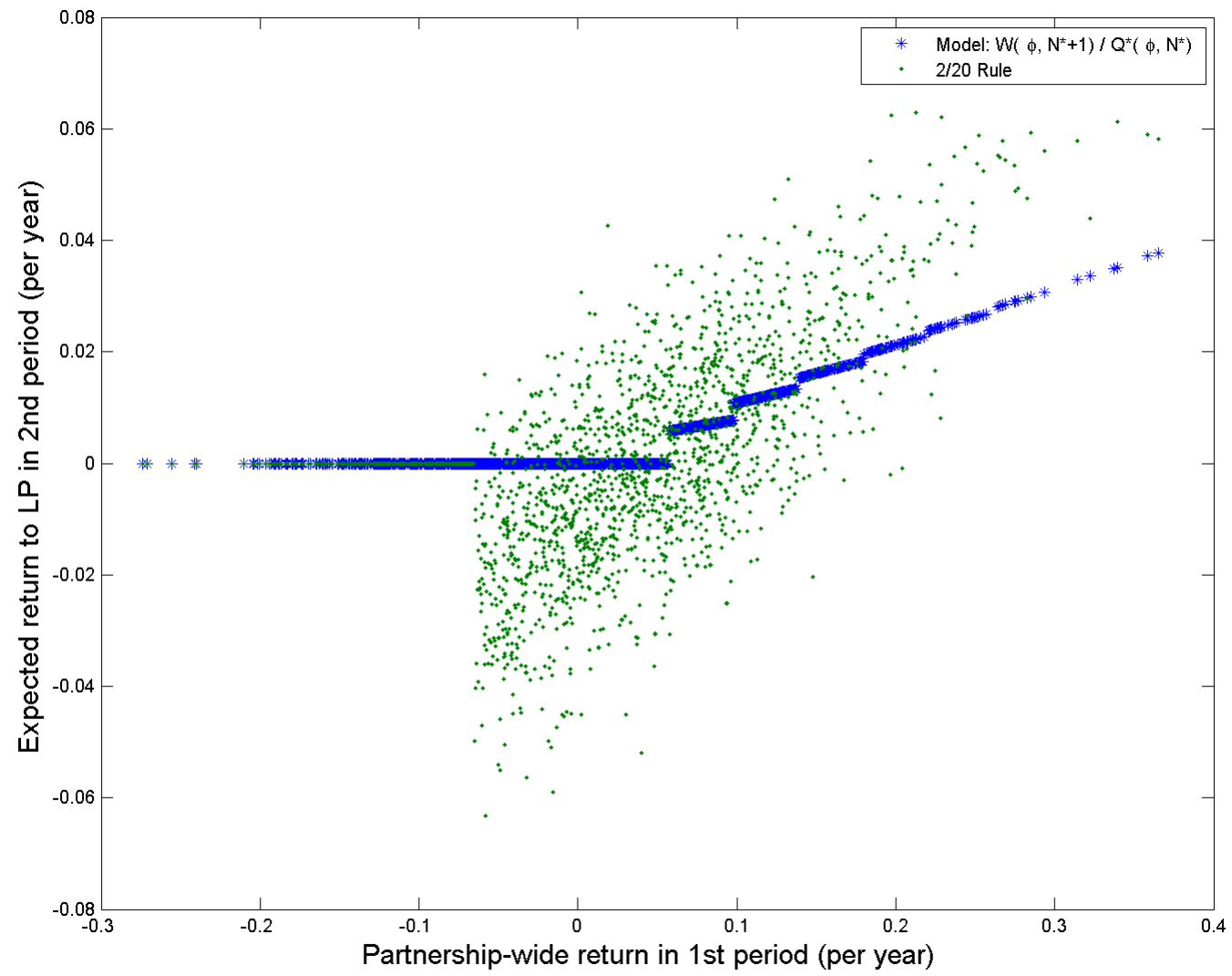

Figure 6: Expected returns earned by incumbent LPs in second period, based on the model and based on a $2 / 20$ rule, as a function of of first-period partnership-wide excess return. 


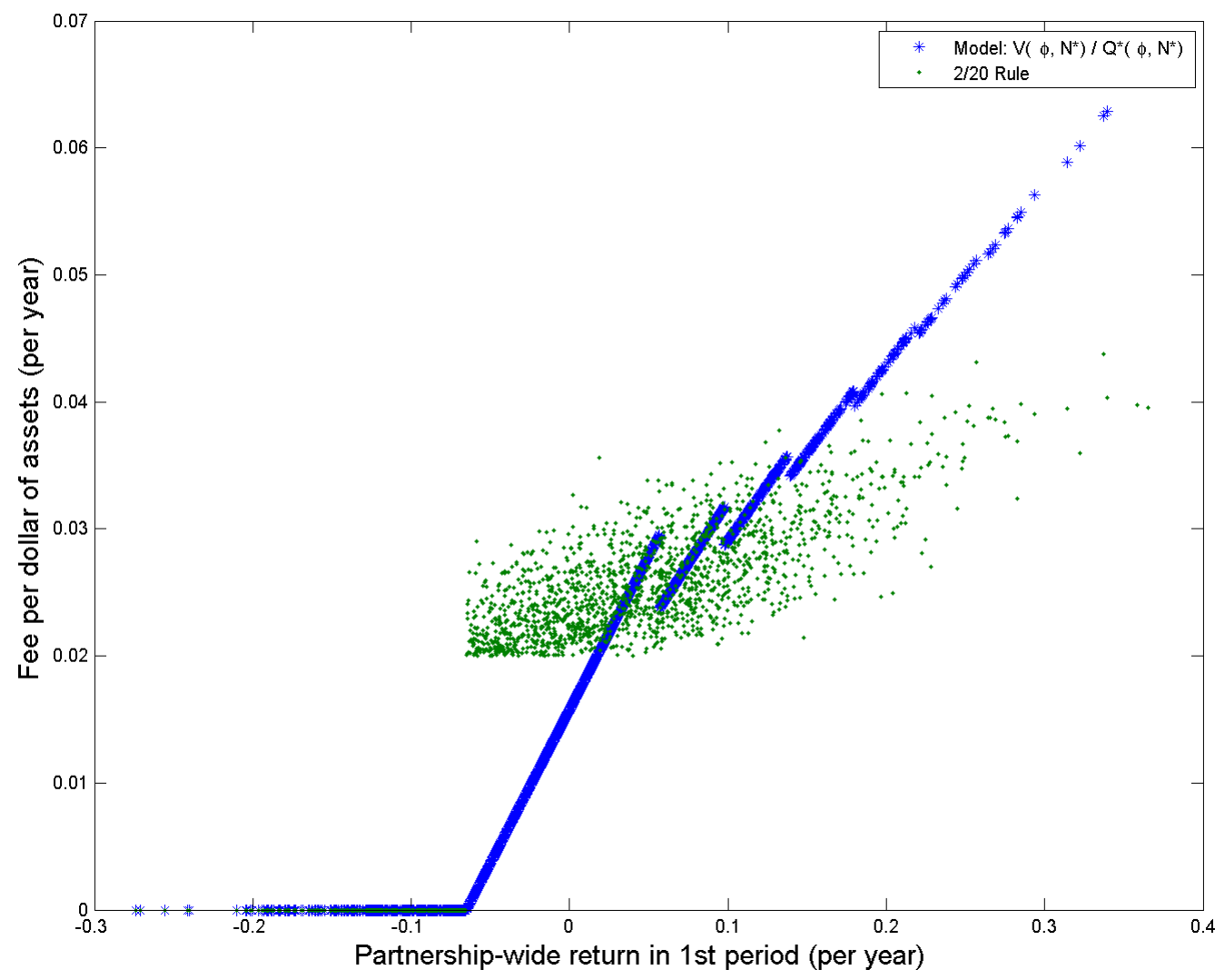

Figure 7: Expected fees earned by incumbent GPs in second period, based on the model and based on a $2 / 20$ rule, as a function of of first-period partnership-wide excess return. 